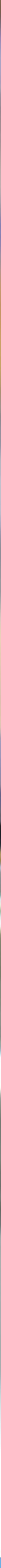

Evaluation of the presence of potential hazardous substances from plastic and textile fibre recycling

Ruud J.B. Peters, Anna K. Undas and Stefan P.J. van Leeuwen

WAGENINGEN

UNIVERSITY \& RESEARCH 



\section{Evaluation of the presence of potential hazardous substances from plastic and textile fibre recycling}

Ruud J.B. Peters, Anna K. Undas and Stefan P.J. van Leeuwen

This research has been carried out by Wageningen Food Safety Research, institute within the legal entity Wageningen Research Foundation. 
Peters R.J.B., Undas A. Van Leeuwen S.P.J., 2020. Potential hazardous substances that rise from plastic and textile fibre recycling and analytical/in vitro assay approaches to evaluate their presence. Wageningen, Wageningen Food Safety Research, WFSR report 2019.017. 46 pp.; 4 fig.; 1 tab.; 102 ref.

Project number: 1297377001

Project title: Recycling and end-of-life strategies

Project leader: R.J.B. Peters

This report can be downloaded for free at https://doi.org/10.18174/515071 or at www.wur.eu/foodsafety-research (under WFSR publications).

(c) 2020 Wageningen Food Safety Research, institute within the legal entity Wageningen Research Foundation. Hereinafter referred to as WFSR.

The client is allowed to publish or distribute the full report to third parties. Without prior written permission from WFSR it is not allowed to:

a) publish parts of this report;

b) use this report or title of this report in conducting legal procedures, for advertising, acquisition or other commercial purposes;

c) use the name of WFSR other than as the author of this report.

P.O. Box 230, 6700 AE Wageningen, The Netherlands, T +31 (0)317 4802 56, E info.wfsr@wur.nl, www.wur.eu/food-safety-research. WFSR is part of Wageningen University \& Research.

This report from WFSR has been produced with the utmost care. However, WFSR does not accept liability for any claims based on the contents of this report.

WFSR report 2019.017 


\section{Contents}

$\begin{array}{ll}\text { Summary } & 5\end{array}$

1

$\begin{array}{ll}\text { Introduction } & 7\end{array}$

2

Recycling of plastics and textiles: Processes and contaminants

2.1 Recycling of thermoplast materials

2.2 Recycling of thermoset materials and composites 9

$\begin{array}{ll}2.3 \text { Recycling of textiles } & 10\end{array}$

Additives in plastics and textiles: Hazardous substances

4.1 Contaminants in recycled plastic. 13

4.2 Contaminants in composites $\quad 15$

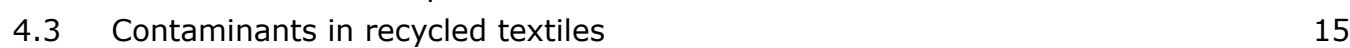

4.4 Environmental contaminants due to recycling processes 16

Analytical and bioanalytical approaches for additives and NIAS identification in recycled plastics and textiles

$\begin{array}{lll}5.1 & \text { Legislative framework } & 17\end{array}$

$\begin{array}{lll}5.2 & \text { Methods for (recycled) plastics and textiles } & 18\end{array}$

5.3 Sample extraction and clean-up for NIAS in plastics $\quad 18$

5.4 Sample extraction and clean-up for NIAS in textiles 19

5.5 Targeted methods detection 19

5.6 Comprehensive suspect screening and non-target analysis 19

5.7 Instrumental (surface ionisation) screening techniques 22

5.8 Combining chemical analysis and bioassays $\quad 22$

$\begin{array}{lll}5.9 & \text { Safety assessment frameworks } & 24\end{array}$

$\begin{array}{ll}\text { References } & 29\end{array}$

Annex 1 An overview of $\mathbf{2 3 8}$ hazardous substances likely associated with plastic packaging

Annex 2 An overview of 43 classes of hazardous substances used in the textile sector 



\section{Summary}

Plastics are highly diverse and the most common materials used for packaging foodstuffs. However, the steadily increasing production of plastic with increasing amounts of fossil-based plastic waste causes severe environmental problems. Comparable with plastics, the textiles and apparel industry is one of the largest and fastest growing global industrial sectors owing to the greater productivity in mass production processes. In recent times, there is an increased awareness of the impacts of the existing linear supply chain of the textile and apparel industry. For plastics and textiles, the recovery of materials and energy, specifically through the application of recycling technologies, would greatly contribute to the vision of a circular economy model. The instalment of a circular economy could contribute to a more sustainable future for generations to come.

The successful recycling of plastics and textiles depends, apart from technical aspects, to a large degree on the safety of the products resulting from recycling. The safety of recycled products is a prerequisite for societal acceptance of recycled plastics and textiles. The transition to a circular economy of plastics and textile fibers will not be accomplished if no guaranteed safe products can be delivered to the market. The evaluation of the safety of recycled plastics and fibers is crucial, but a framework for evaluation of potential hazardous substances and associated risks for the consumer is virtually absent. More specifically, a legislative framework, risk assessment framework, and relevant testing strategies are urgently needed.

In this report the recycling and reprocessing of thermoplastic materials, composites and textiles have been reviewed and described. In the production of plastics and textiles many substances are used that are highly hazardous and therefore of significant concern for occupational health. During the recycling or the use of recycled materials these substances may be released to products or the environment. Plastics may be a source of contamination in the recycling process if they are mixed with other plastics and well known plastic additives have been found in children toys and food contact materials produced from recycled plastics. Since composites are rarely recycled no information was found about contaminants in recycled materials. For textiles it was found that the knowledge base surrounding substances problematic for recycling is very limited.

For the analysis of hazardous substances or non-intentionally added substances (NIAS) in recycled plastics or textiles two strategies are applied: targeted analytical methods for the analysis of predicted and known substances, and untargeted or screening methods to analyze unknown substances. Targeted analysis are performed using GC- and LC-MS based methods and dedicated substance libraries for identification. For untargeted analysis GC an LC techniques are used in combination with high resolution mass spectrometry (HRMS) techniques like Orbitrap or QTOF mass spectrometry. In untargeted analysis in silico tools are gaining importance in the identification of substances. Recent publications describe the use of so-called explorative methods, an untargeted analytical strategy to estimate the concentration and chemical structure of unknowns. However, a comprehensive analysis is not realistic and therefore a risk prioritization is required to identify the substances that most likely have adverse health effects.

The combination of bioassays with sensitive analytical techniques, so-called effect directed analysis, is another promising and efficient way of identifying unknows and NIAS and their hazard to human exposure. In vitro bioassay based testing allows for a rapid evaluation of multiple toxicological endpoints. Positive sample extracts or fractions thereof can be further analyzed with GC- or LC-HRMS techniques to identify the toxic substances. Finally, safety assessment frameworks may be used for the detection and identification of unknown substances in complex samples. In such frameworks the number of analytes that have to be identified is reduced by using a threshold based on the threshold of toxicological concern (TTC). By identifying substances of highest concern, the resources available for experimental testing can be attributed in a more efficient way. 
For a successful implementation of safe recycling processes and recycled products, there is an urgent need for comprehensive approaches for identification and quantification of hazardous substances, and to assess their safety. The first step in this process is method development for the identification and quantification of hazardous substances in recycled plastics and textiles. Currently such methods are virtually absent, especially for textiles. The literature review has revealed that targeted and untargeted mass spectrometric methods are needed. However, since many of the substances detected in such analyses may be NIAS or otherwise unknowns, identification is a difficult and time-consuming process. For efficient identification such techniques have to be combined with compound databases that may be compiled from different sources. Since it is unlikely that all detected substances can be identified an effect-directed method would be very helpful to detect and finally identify potentially hazardous substances. However, as with the other analytical techniques, effect-directed analysis and especially the coupling of the bio-assay and the instrumental technique is not standard and has to be developed. Finally, hazardous substance prioritization schemes and techniques as TTC and CoMSAS for risk assessment have not been used for recycled plastic and textile materials and so this is also a new playing field to be developed. 


\section{Introduction}

Plastics are highly diverse and the most common materials used for packaging foodstuffs. In 2015, almost 20 million metric tons of plastic packaging were used in Europe (Plastics Europe, 2016), generating approximately $30 \mathrm{~kg}$ of plastic packaging waste per inhabitant per year (Eurostat, 2017). The steadily increasing production of plastic with increasing amounts of fossil-based plastic waste causes severe environmental problems. This includes a high energy demand during production, the consumption of fossil fuels and accumulation of plastic waste in landfills and natural environments. Approaches to slow-down the demand for virgin plastic have been developed although the recycling of plastic materials is currently achieved only for a small percentage of all plastic produced. The instalment of a circular economy could contribute to a more sustainable future for generations to come. This circular economy is based on three main pillars; stop littering by setting up waste management systems, circular use of materials and use of bio-based feedstock to produce virgin materials (Ellen McArthur Foundation, 2017a). Waste management systems and recycling technologies are in place or in development for paper and board and for some plastic waste (mainly food packaging materials), but many more carbon containing materials need developments towards circular use. The recycling and reprocessing of thermoplastic materials can generally be performed relatively easily from a practical and technological point of view (Soroudi and Jakubowicz, 2013; Ambrose et al., 2002: Maris et al., 2018). Two other important and more challenging material classes are composites and textiles.

Composites are a combination of a thermoset resin with a carbon fibre reinforcement. Thermoset materials are classified amongst the most difficult materials to recycle and therefore the recycling of composites is rare and focuses on the recovery and reuse of the carbon fibre reinforcement.

The textiles and apparel industry is one of the largest and fastest growing global industrial sectors, owing to increasing population, the rise in consumption, the diverse applications of textiles, and greater productivity in mass production processes. With a 1.3 trillion USD annual revenue in 2016 (Euromonitor International Apparel \& Footwear, 2016), the global clothing industry is the largest consumer of textiles. Annual production has nearly doubled since 2000, surpassing 100 billion units in 2015 with apparel consumption expected to rise $63 \%$ by 2030 . This increase is partly due to the fast fashion industry, which relies on shorter production cycles and style turnaround, often at lower prices, enabling a larger selection and choice for consumers (Ellen McArthur Foundation and Circular Fibres Initiative, 2017). In recent times, there has been great interest in increasing the reuse and recycling of textiles because of an increased awareness of the impacts of the existing linear supply chain of the apparel industry. Reuse refers to the utilization of a product in its original form while recycling refers to the conversion of waste into products. Recovery of materials and energy, specifically through the application of recycling technologies would greatly contribute to the vision of a circular economy model as proposed by the Ellen McArthur Foundation (Ellen McArthur Foundation and Circular Fibres Initiative, 2017a).

It is crucial to determine the safety of recycled products, and it's a prerequisite for societal acceptance of recycled plastics and textile fibres that these products are safe to use. A framework for safety (risk) evaluation of potential hazardous substances is needed, and state-of-the-art chemical analysis technologies are required for that. Next to known hazardous substances (e.g. BPA, PFASs, BFRs, dioxins), pigments and additives, also unknown substances (non-intentionally added substances, NIAS) need to be targeted. In all cases circular use could lead to accumulation of hazardous substances and new analyses strategies are needed especially for NIAS. The identification of NIAS has not been reported in recycled plastics, contrary to recycled paper (Peters et al., 2019). In this study an overview of the potential hazardous substances that arise from plastic and textile recycling will be made via literature research. It will be assessed if current analytical methods for the determination of NIAS and other substances in paper/board recycling can be extended to plastic materials. Finally, invitro testing approaches for the evaluation of toxic effects of recycled materials will be studied. 


\section{Recycling of plastics and textiles: Processes and contaminants}

Plastic and textile waste can be recovered either by mechanical recycling (primary recycling substituting virgin materials in the same application and secondary recycling), by producing chemical building blocks (monomers, tertiary recycling), or the waste can be turned into energy (quaternary recycling) (ASTM, 2000: Hopewell et al., 2009). Recycling is most commonly achieved by mechanical and, to a much lower extent, by chemical processes. Mechanical recycling of plastics includes cleaning, grinding, remelting and regranulating steps (Ignatyev et al., 2014). During mechanical recycling, polymer backbones are partially degraded because shredding and heating will lead to breakage of intramolecular bonds resulting in a lower molecular weight distribution and changed mechanical and optical properties of the recycled polymer. Some types of plastic additives, e.g. plasticizers, antioxidants and stabilizers, may form unintended reaction products, thereby losing their original function. To compensate such unwanted changes, mechanical recycling processes often require the addition of virgin polymers and/or additives. The application of mechanically recycled plastic in contact with food requires special attention because it may not only contain degradation products of polymers or additives, but also incidental contaminants arising from previous use and misuse by consumers, cross-contamination from waste disposal, and environmental contaminants. Chemical recycling processes depolymerize plastics into monomers which are subsequently used for repolymerization of virgin-like materials (Geyer et al., 2016). Economic and ecological issues currently limit the large-scale application of chemical recycling processes.

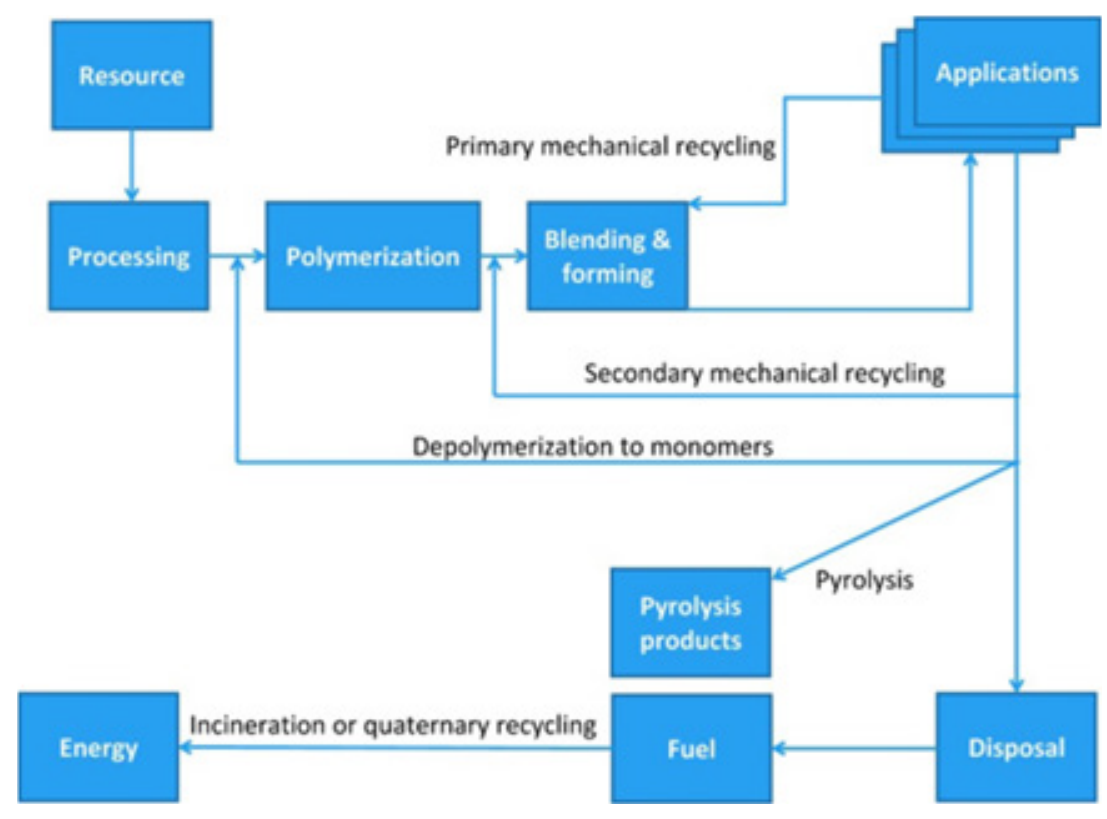

Figure 1 Most common recycling methods and their position in a lifecycle of an application (Ignatyev et al., 2014).

\subsection{Recycling of thermoplast materials}

The most recycled thermoplast material is polyethylene terephthalate (PET). It is completely recyclable by thorough washing and re-melting, or by chemically breaking it down to its monomers to make new PET resin (ILSI, 2017). Recycling of PET beverage bottles has become standard due to the relatively high inertness of $\mathrm{PET}$, its resistance to higher temperatures, and the establishment of collection systems for food-contact grade PET. Several dozens of bottle-to-bottle PET (primary) recycling processes have been developed in the last 25 years and this is a good example of primary 
recycling. PET can also be recycled into fleece as an example of secondary mechanical recycling (downcycling to a product with less value). Finally, PET can also be cleaved by some reagents, like water (hydrolysis), glycols (glycolysis) or alcohols (alcoholysis). According to the reagent used, different products are obtained. Hydrolysis is a recycling method that involves a reaction of PET with water in an acid (DeCarvalho et al., 2006), alkaline or neutral environment (Karayannidis and Achilias, 2002), leading to total depolymerization into its monomers. Chemical recycling of PET by glycolysis involves ethylene glycol insertion into PET chains to give bis(hydroxyethyl) terephthalate (BHET), which is a substrate for PET synthesis and other oligomers (Karayannidis and Achilias, 2007). Chemical recycling of PET by methanolysis involves PET degradation by methanol at temperatures between 180 and $280^{\circ} \mathrm{C}$ and pressures from 2 to $4 \mathrm{MPa}$ with the main products being dimethyl terephthalate (DMT) and ethylene glycol (EG) (Yang et al., 2002).

As for PET, mechanical recycling is the most used process for recycling polypropylene (PP), lowdensity polyethylene (LDPE) and especially high-density polyethylene (HDPE). The HDPE material is mechanically separated from the other plastics, shredded and melted down to further refine the polymer. The plastic is then cooled into pellets which can be used in manufacturing. Chemical recycling of polyethylene's involves pyrolysis, gasification, liquid-gas hydrogenation, viscosity breaking, steam or catalytic cracking, similar to those employed in the petrochemical industry (Schillias et al., 2018). Catalytic cracking and reforming facilitate the selective degradation of waste plastics. In particular, polyethylene has been targeted as a potential feedstock for fuel (gasoline) producing technologies. PE thermally cracks into gases, liquids, waxes, aromatics and char. There is a growing interest in developing value added products such as synthetic lubricants via PE thermal degradation. Polyurethanes (PU) are one of the most versatile groups of plastic materials, with a variety that stretches from flexible/rigid foams and thermoplastic elastomers to adhesives, paints, and varnishes. PU production is expensive compared with mass-produced plastic materials (e.g., polyolefin plastics), which is the reason for the development of recycling methods for PU wastes since the 1960s (Behrendt and Naber, 2009). As with the other plastics, recycling routes for PU can be divided into 'mechanical', 'chemical' and 'energy'. Mechanical recycling covers grinding, compression moulding, adhesive pressing and bonding of PU wastes. Chemical recycling covers two different technological routes: chemolysis and petrochemical type processes. The chemical route uses mostly hydrolysis, aminolysis or a glycolyis approach. Energy recovery refers to incineration of PU waste, decomposition (by pyrolysis or hydrogenation) and the combustion of products.

\subsection{Recycling of thermoset materials and composites}

Due to an increasing number of applications that use lightweight thermoset materials and restrictions on landfill solutions throughout the EU, the development of thermoset recycling strategies has accelerated in recent years (Yang et al. 2012). Mechanical recycling uses high force and shear to achieve a size reduction of the waste component into uniformly sized flakes. These flakes are treated with hammer mills or high-speed mills into finer products in the millimetre to micrometre range. A disadvantage of this approach is that the thermoset matrix and the carbon fibres are not treated separately and as such any orientational advantage of the filler material is lost. The powder obtained after mechanical grinding is generally only used as a filler in new, for example thermoplastic, materials (Bernardeau et al., 2018). Thermal recycling can be divided in aerobic and anaerobic combustion known as incineration and pyrolysis. Incineration leads to recovery of energy and in some processes to recovery of the glass and carbon fibres (Pickering et al., 2000). Pyrolysis will break down the thermoset matrix into lower molecular weight organic substances of which the chemical structure is related to the original material which can potentially be used as feedstock for further chemical processing (Yang et al., 2012: Al-Salem et al., 2017). Since the recovered carbon fibres are not affected by oxidation this leads to a higher quality recycled product and therefore pyrolysis is seen as the most optimal thermal recycling treatment for thermoset materials or composites. In chemical recycling a liquid medium is used to degrade and dissolve the thermoset matrix so the reinforcing carbon fibres can be regained. Similar as to pyrolysis, the degraded and dissolved organic substances can be reclaimed from the solvent and be re-used as molecular building blocks (Kuang et al, 2018: Sokoli et al., 2017). The cracking of the thermoset matrix, mostly flexible or rigid foam mixtures, produces a polyol which can be reintroduced into the PU raw material cycle. An issue is that the separation of organic substances from the solvent requires a lot of 
energy and that the frequent use of hazardous solvents makes the impact of chemical recycling questionable (Shuaib and Mativenga, 2017).

\subsection{Recycling of textiles}

Textile recycling processes have long existed, but have been greatly influenced by factors such as high prices, volume, and availability of virgin raw materials, which have limited the ability to be integrated as established and economically viable operations. Processes such as re-spinning of post-industrial and post-consumer materials, pulping of cotton and linen, and non-woven material production have existed for centuries, with variations of such operations currently practiced. Comparable to the situation for plastics (schematically presented in Figure 1), four categories of recycling technologies exist and are summarized as follows (Wang, 2010):

- Primary: recycling material in its original form for recovery of equal value;

- Secondary: processing post-consumer product usually by mechanical means into product with different physical and/or chemical properties (mechanical recycling);

- Tertiary: processes such as hydrolysis and pyrolysis, in which waste is converted to basic chemical constituents, monomers, or fuels (chemical recycling);

- Quaternary (recovery): waste-to-energy conversion processes such as incineration of solid waste, or utilization of heat generated.

Specific to textile materials recovery, common processes include mechanical and chemical recycling methods. Mechanical recycling processes are categorized as a secondary recycling approach.

Processes include: cutting of sorted fabrics for use as wiper rags, shredding and pulling of textile materials into fibres, re-bonding or respinning into new yarns or fabrics, melting and re-extruding, reblending (may include proportions of virgin material) or respinning to produce new yarns and threads, or textiles (Peterson, 2014). Chemical recycling processes are categorized as a tertiary recycling approach, and include processes in which the chemical structure of the material is either broken down partially or fully (depolymerization), followed by re-polymerization to virgin material, or through the dissolution and melting processes, from which the material is drawn or extruded into reusable textile fibre (Peterson, 2014). Chemical recycling of cellulosic fibres has been developed with ongoing advancements in technology towards scale-up, while the recycling of synthetics (nylons and polyesters) include some full-scale developments, but is limited to a few suppliers. Nevertheless, developments in demonstrated technologies are expected to be advanced in the coming decades.

Mechanical recycling of polyester consists of a re-melt process (or melt recycling). The process consists of the following main steps (Arthur, 2017):

- Collection, sorting, separation, and removal of contaminants or non-target materials;

- Reduction of size - crushing, grinding, shredding, or pulling;

- Heating/re-melting, and extrusion into resin pellets;

- Melt extrusion into textile fibres;

- Processing of textile fibres to fabric.

The polyester recovered from mechanical recycling is often used in lower value applications, due to the loss of physical properties, degradation, and contamination during use cycles and processing. Post-consumer PET bottles are most often recycled into PET yarns. The chemical recycling pathways for PET have already been described in the previous section "recycling of thermoplast plastics" (2.1) and include processes which break down (depolymerize) the polymer into its components (monomers, oligomers, other intermediates). Chemical treatment in the recycling process may also facilitate the separation of PET from other materials, such as blended textile fibres (i.e. elastane or cotton), or dyes and chemical finishing, as well as the creation of other end products of equal value (Aguado and Serrano, 2007). The most common depolymerization methods include: hydrolysis, methanolysis, glycolysis, or hybrid routes.

The process for the mechanical recycling of nylon involves the same steps as that for polyester. Due to its lower melting temperature (compared to PET), nylon is highly susceptible to contamination by microbes, bacteria, and non-recyclable impurities remaining in the material, and thereby requires a 
cleaning process prior to recycling (Muthu et al., 2012). Chemical recycling of nylons includes a depolymerization process followed by distillation to obtain and recover their monomeric constituents: caprolactam (for Nylon-6), and HMDA and adipic acid (for Nylon-6,6).

The mechanical recycling of cotton is well established and is applied to both pre- and post-consumer waste and generally entails the respinning of recycled material combined with virgin material without additional chemicals (Ellen McArthur Foundation, 2017b). The majority of chemical recycling processes of cotton is in the development stage or close to commercial adoption, and include either dissolution processes to recover the cellulosic fibres or depolymerization processes to generate other by-products. The chemical recycling process of cotton is based on the dissolution of cellulose. Two main routes which have been explored include the depolymerization of glucose monomers for use in other applications, or a polymer dissolution route where the separation and regeneration of cellulosic fibres occurs by use of solvents (Li-Carrillo, 2016). 


\section{Additives in plastics and textiles: Hazardous substances}

Many substances used to make plastics, including packaging plastics, are highly hazardous and therefore of significant concern for occupational health. During the subsequent use, disposal and recycling of the plastics packaging, substances present in the plastic may transfer into products such as foods or cosmetics, or into the environment. Plastic recycling can also result in accumulation of hazardous substances in the recycled materials and therefore, a detailed assessment of substances associated with plastic packaging is necessary. Recently, a number of publications have emerged that give an overview of substances associated with plastics or plastic packaging. Stenmarck et al. (2017) have produced an overview that was based on reports from the Danish Ministry of the Environment and includes substances from the following lists of hazardous substances: The Danish EPA's list of undesired substances (LOUS), The SVHC Candidate List under REACH, The Norwegian list of priority substances, ECHA's Registry of Intentions, CMR-substances likely to be present in plastic toys, and recognized alternatives to problematic phthalates and BFRs. Hahladakis et al. (2018) categorized the most commonly used additives in plastics and plastic packaging (mostly food packaging) and described their uses, applications and properties. Groh et al. (2019) produced an overview of known plastic packaging-associated substances and their hazards. They compiled a database starting from the American EPA's Chemicals and Product Categories database and Ernest Flick's Plastics additives database and combining these with a number of further overviews and listings. In this study the overviews of the three references are combined into an overview of 238 most hazardous substances likely associated with plastic packaging. The list of these substances is given in Annex 1 .

As with the plastics, an extensive amount of substances is used throughout the manufacturing stages of textiles, from textile fibre production, through to treating, dyeing, and finishing processes, often comprising $5-15 \%$ of a garment's weight (Safer Made, 2018). Substances may be used to provide colour and impart function to textiles. To convert raw materials into textiles, it has been cited that 8,000 different substances are used (Safer Made, 2018). Various substances have been identified to be toxic to human health and produce a multitude of effects on the environment, notably water pollution. Increased awareness and concern regarding effects of chemical usage in the industry has prompted widespread efforts to create and implement chemical management practices, identification systems, standards, policies, and legal requirements. There have also been extensive efforts towards new safe and sustainable chemistry and processes, as well as innovation around new or alternative substances. In the "Safer Chemistry Innovation in the Textile and Apparel Industry" report by Safer Made chemicals used in the textile sector were evaluated and organized into 43 classes of substances, and six broad substance groups which are: amines, dyes and residuals, halogenated substances, metals, monomers and solvents and process aids (Safer Made, 2018). The list of 43 classes of substances is given in Annex 2. 


\section{$4 \quad$ Contaminants in recycling plastics and textiles}

Whereas in the northern part of the world plastics production, use and recycling is regulated to varying degrees, in many developing countries plastic recycling is often not controlled by an appropriate regulatory framework, and environmental protection is poorly enforced, resulting in significant contamination of the ambient environment in areas where plastic is recycled. Uncontrolled recycling can also result in the transfer of potentially harmful substances into recycled plastics. This section deals with contaminants in plastics and textiles as a possible result of recycling and environmental and human exposure aspects of recycling.

\subsection{Contaminants in recycled plastic.}

The application of recycled plastics is limited by two factors: The polymer purity and the molecular purity. The former restricts the use of recycled material to thick-wall applications with less mechanical demands. Most of the polymers are not compatible with each other, i.e. their blends have mechanical properties that are inferior to those of the pure constituents. Examples are PET impurities in PVC, in which solid PET lumps form in the PVC phase. This leads to significantly downgraded properties and consequently less-valuable end products (Hopewell et al., 2009). The molecular purity restricts the use of recycled plastics to non-food applications only. Only for recycled PET is the molecular contaminant limited and is re-use possible. Differently from PE, PP, PS and PVC, PET only absorbs very limited amounts of fat, mineral oil and other molecular materials. For the other materials it is questionable whether recycled material can be used as a food contact material (FCM). The collected used plastics waste are contaminated by e.g. oil/food/residues, and during recycling the materials will be treated with washing agents, solvents, and heated to $>125^{\circ} \mathrm{C}$. These new products potentially contain a wide range of molecular contaminants (i.e. residual contaminants and de-novo chemical reaction products resulting from treatments, the so-called non-intentionally added substances, NIAS). Information about what the nature of the molecular contaminants and NIAS in plastics is limited and will also often not be known by the manufacturer.

Additives fulfil a large variety of different functions in plastic polymers by improving production processes as well as appearance and performance of the final products. In Europe, around 600 substances are authorized as additives and polymer production aids for plastic FCMs (EC, 2011). Additives are generally substituted during recycling to compensate losses in functionality while residual additives and their breakdown products remain in the plastic material. Dutra et al. (2014) measured the migration of non-volatile and inorganic residual substances from post-consumer recycled PET, as well as from multilayer packaging material containing postconsumer recycled HDPE. Tests were carried out using food simulants. Several authorized plastic additives were measured in recycled PET, including the plasticizers di-isononyl adipate (DINA) and di-isononyl phthalate (DINP), the optical brightening agent Uvitex OP and the slip agent oleamide. Several inorganic contaminants, determined by inductively coupled plasma mass spectrometry, were found but all were below the acceptable levels. Keresztes et al. detected several phthalates in water samples from PET bottles with 20-30\% recycled content. In contrast, these phthalates were not found, or only in low concentrations, in water samples from bottles composed of virgin PET (Keresztes et al., 2013). It's not so clear where these phthalates should come from since they are not needed as additives in PET. Results of Pivnenko et al. (2016), who analysed the levels of nine phthalates in plastic waste samples, seem to suggest that these phthalates were introduced into post-consumer PET as irregular external contaminants derived from other polymer types during the collection stage.

A report from the Norwegian Environment Agency from 2013 outlined the presence of 43 substances potentially used in plastics and that are considered hazardous and which may be limiting the possibilities for plastic recycling (NEA, 2013). The report did not explicitly include NIAS potentially present in plastic products, waste plastics and recycled plastics. Thus, the list of substances actually 
present in plastics can potentially be longer. Nevertheless, among the substances identified in the report main groups of substances included phthalates, toxic metals, brominated flame retardants (BFRs), poly-aromatic hydrocarbons (PAHs), etc.. Phthalates are mostly used as plasticizers in plastic production, with the largest share of the plasticizers market being attributed to polyvinyl chloride (PVC) production. Depending on their carbon chain length, phthalates are commonly divided into low and high molecular weight (i.e. LMW and HMW, respectively). LMW phthalates are prone to migration, making them more relevant for human toxicity. This has also resulted in restrictions on their use in selected applications in plastic materials (e.g., food-contact articles and children's toys) (EU, 2011). Di-iso-butyl phthalate (DiBP), di-(ethylhexyl) phthalate (DEHP) and dibutyl phthalate (DBP) are LMW phthalates found in the majority of plastics (Pivnenko, 2016). DEHP is the dominant phthalate found in relatively high concentrations (up to $2700 \mathrm{mg} / \mathrm{kg}$ ) in the majority of the plastic samples. Several sources of plastics were evaluated for their phthalate content (Pivnenko et al., 2016). The results showed that virgin and recycled industrial plastics (group 1) have similar phthalate content. Furthermore, residual and source-segregated waste plastics and recycled household plastics (group 2) were also similar as to their phthalate content. On the other hand, group 1 and group 2 were significantly different, with group 2 having higher phthalate content. Based on the systematic statistical assessment of results for the evaluated samples, this could indicate that phthalates are added in later stages of plastic product manufacturing (labelling, gluing, etc.) and are not removed in the re-processing of plastics, making recycling a potential source of phthalates in products based on recycled waste material.

Different groups of contaminants, e.g. oligomers, additives and their degradation products, as well as substances derived from previous uses, have been reported in recycled plastic (Camacho and Karlsson, 2000; Dutra et al., 2011; Nerin et al., 2003). Flavor, odor and aroma substances from previous uses belong to common contaminants in post-consumer plastic packaging. The presence of citrus-based essential oils has been attributed to soft drinks stored in PET bottles (Bayer, 2002). According to the same reference other substances from food-grade PET used in non-food applications such as mouthwash, personal hygiene and household cleaners also contributed to the contamination of post-consumer PET. Similar substances were measured in recycled, but not in virgin HDPE (Camacho and Karlsson, 2000). Furthermore, 11 esters and 5 alcohols were only identified in recycled, but not in virgin HDPE and their origin was assigned to the previous use of the packaging, e.g. personal hygiene products or cleaning agents.

Oligomers are unintentionally formed by-products in the synthesis of plastics. Additionally, they may be generated during the recycling of polymers. Linear and cyclic oligomers have been measured in recycled PET with di- and trimers being the predominant species (Lopez et al., 2014). Acetophenone and benzaldehyde are oxygenated derivatives of styrene, which have been found in higher relative abundances in recycled than in virgin PS samples (Vilaplane, 2007). Kanwal et al. (2007) measured thermal degradation of PS after recycling and found increased levels of migration into vegetable oils at high temperatures.

Plastic samples, including waste and recycled plastic waste from households and industry, and virgin plastic were analysed for 15 selected metals. Samples of reprocessed household waste contained the overall highest concentrations of metals, potentially related to the use of metal-containing additives (e.g. fillers) to enhance the mechanical properties of plastic during recycling. While the elevated metal concentrations in the recycled plastic did not exceed legal limits, it is important to be aware that metal concentrations are higher in recycled plastic from household plastic waste and that a continuous increase in plastic recycling rates may lead to even higher metal concentrations in the future (Eriksen et al., 2018). In addition metal-containing additives have direct impact on the recyclability of plastics or even support the degradation of plastics (Pivnenko et al., 2016). In particular metal salts or oxides such as $\mathrm{Fe}_{2} \mathrm{O}_{3}, \mathrm{Cu}_{\mathrm{x}} \mathrm{O}, \mathrm{ZnO}$ and $\mathrm{TiO}_{2}$ have been found to act as pro-oxidants and photo-oxidation catalysts (Shawaphun et al., 2010).

Contaminants can also be derived from non-food grade plastics by transfer of certain groups of additives into new recycled products, a problem especially with more sensitive use areas. For instance, brominated and phosphorous flame retardants and phthalates have been found in children toys from recycling (Chen et al., 2009: Ionas et al., 2014: Lee et al., 2014). Flame retardants have also been 
measured in samples of black plastic FCMs and household products from the European market (Samsonek and Puype, 2013: Puype et al., 2015: Puype et al., 2017). Flame retardants are commonly divided into four groups in accordance to the main chemical constituent used, i.e. halogenated organic, phosphorus-containing, nitrogen-containing and inorganic (Birnbaum and Staskal, 2004). The largest market share is attributed to a subgroup of halogenated organic - brominated flame retardants (BFRs). The subgroup contains well-established BFRs produced in large volumes, i.e.

hexabromocyclododecane (HBCD) and tetrabromobisphenol A (TBBPA), as well as emerging phenolbased BFRs (e.g., 2,4-dibromophenol (2,4-DBP) and 2,4,6-tribromophenol (2,4,6-TBP)). While HDPE contained among the lowest concentrations of HBCD and TBBPA, packaging waste HDPE (both sourcesegregated and residual) also contained the highest concentrations of 2,4-DBP and 2,6-dibromophenol (2,6-DBP). In addition to the direct use of selected BFRs, relatively high concentrations of 2,4-DBP (240 ng/g), 2,6-DBP (250 ng/g) and TBBPA (7000 ng/g) in a sample could be attributed to thermal degradation of TBBPA and production of dibromophenols as by-products in recycling. Puype et al. (2015) analysed 10 selected food contact utensils (produced of recycled materials) of which seven contained a bromine level ranging from 57 to $5975 \mathrm{mg} \mathrm{kg}^{-1}$. The BFRs that were present were TBBPA, decabromodiphenylether (decaBDE), decabromodiphenylethane (DBDPE) and 1,2-bis(2,4,6tribromophenoxy)ethane (BTBPE). In all cases when bromine was detected at higher concentrations, concurrently antimony was also detected, which confirms the synergetic use of antimony in combination with BFRs. Finally, the plastic recycling process may also influence the transformation of contaminants contained in the waste material being recycled. As an example, among the three isomers of HBCD measured, a-HBCD was found in relatively higher concentrations compared to $\beta$ - or $\mathrm{Y}$-HBCD (Pivnenko et al., 2017). This contradicted the common composition of commercial HBCD mixtures, where $\mathrm{Y}-\mathrm{HBCD}$ is the dominant isomer. Since exposing $\mathrm{HBCD}$ to temperatures $>100^{\circ} \mathrm{C}$ promotes the transformation of $\mathrm{Y}-\mathrm{HBCD}$ to $\mathrm{a}-\mathrm{HBCD}$, temperatures commonly applied in thermoplastics re-processing $\left(135-245^{\circ} \mathrm{C}\right)$ can alter the diastereometric ratio of a HBCD mixture and explain the prevalence of the a-HBCD in samples of recycled plastics.

\subsection{Contaminants in composites}

Since composites are rarely recycled no information was found about contaminations in recycled composite material.

\subsection{Contaminants in recycled textiles}

It has been identified that substances found in textile materials have potential to impede recycling processes; however, the knowledge base surrounding substances problematic for recycling is limited, and specific impacts have not been characterized. In the current system, information regarding substances and quantities present in textile materials is not generally passed on to potential recycling companies. It would be greatly beneficial to advance the knowledge gaps in this area by improving traceability and the identification of substances in textile materials, and the examination and identification of substances which have been found to interfere with recycling technologies.

In addition to substances of concern there are emerging concerns related to plastic pollution caused by the textile and apparel industry. Synthetic textile fibres like polyester and nylon now dominate apparel. Synthetic polymers tend to persist in the environment and can end up acting as chemical pollutants as well as substrates that magnify the accumulation of other harmful substances in the ecosystem. An article published in Environmental Science \& Technology connects plastic microfiber pollution in the marine environments with emissions from washing apparel made from synthetic textile fibres (Browne et al., 2011). Since (mechanically) recycled textile is expected to contain less strongly bound textile fibres this problem may increase with increasing textile recycling. 


\subsection{Environmental contaminants due to recycling processes}

All four levels of plastic recycling, primary and secondary mechanical recycling, chemical recycling and thermal recovery, are currently implemented worldwide in a different degree to recycle and recover plastic waste. Depending on the type of process this may lead to contamination of the environment and exposure of humans. Moulding and extrusion are key stages in the mechanical material recycling of plastic waste that usually is operated at $200-300^{\circ} \mathrm{C}$, and in this temperature range a lot of hazardous substances such as toxic metals, volatile organic compounds (VOC), phthalates, polycyclic aromatic hydrocarbons (PAH), polybrominated diphenyl ethers (PBDE) and polybrominated dibenzo-pdioxins and furans (PBDD/F) may be released. He et al. (2015) studied VOC emissions during the recycling of different types of plastics and found that especially styrene and other mono-aromatics were emitted during the recycling of ABS and PS plastics. Huang et al. (2013) showed that exhaust gases from plastic waste recycling granulation had an effect on the ambient environment. PAHs were detected inside and outside of the recycling granulation plants area while high levels of the phthalates DBP and DEHP were detected inside the plants. Tang et al. (2015) demonstrated that the surface soils and sediments in areas with plastic recycling plants are contaminated with $\mathrm{Cd}$ and $\mathrm{Hg}$ in concentrations of 0.36 and $0.41 \mathrm{mg} / \mathrm{kg}$ in the soils and 1.53 and $2.10 \mathrm{mg} / \mathrm{kg}$, respectively, in the sediments. Tang et al. (2014) and Labunska et al. (2013) studied the emission of PBDE from plastic waste recycling and found that concentrations of these substances in soils, sediment, human hair and dust were higher in areas containing plastic waste recycling plants. PBDE concentrations in road dust samples from an area with intense mechanical recycling of plastic waste, were 10 to 100 times higher than normal background concentrations (Tang et al., 2016). The open burning of cables and other ewaste plastic resulted in the formation and release of complex mixtures of persistent organic pollutants including chlorinated and brominated dioxins and furans and dioxin-like polychlorinated biphenyls with often particular high levels of brominated and mixed halogenated dibenzofurans suggesting the combustion of PBDE-containing plastics as the principal source (Tue et al., 2016). Gu et al. (2017) investigated the environmental impacts from mechanical plastic recycling and made a sensitivity analyses to evaluate the potential environmental changes occurring by variations in operational process parameters. They concluded that specific focus should be given to the extrusion process, that plastic recycling activities should be centralised, and that material substitution achieved considerable environmental benefit. 


\section{$5 \quad$ Analytical and bioanalytical approaches for additives and NIAS identification in recycled plastics and textiles}

The successful recycling of plastics and textiles depends, apart from technical aspects, to a large degree on the safety of the products resulting from recycling. The safety of recycled products is a prerequisite for societal acceptance of recycled plastics and textiles. The transition to a circular economy of plastics and textiles will not be accomplished if no guaranteed safe products can be delivered to the market. The evaluation of the safety of recycled plastics and textiles is crucial, but a framework for evaluation of potential hazardous substances and associated risks for the consumer is virtually absent. More specifically, a legislative framework, risk assessment framework, and relevant testing strategies are urgently needed.

\subsection{Legislative framework}

A legislative framework covering the safety of recycled products in a broad sense is lacking. The area of food contact materials (FCMs), and particularly the substance safety of plastic FCMs, is regulated in EC regulation 10/2011. This regulates a number of issues: (i) overall and specific migration limits (SMLs) for a wide range of substances; (ii) a list of approved monomers and additives, partly with restrictions and specifications and (iii) the obligation to consider also substances which are not added intentionally, socalled NIAS. This framework focusses on new plastic materials. When it comes to FCMs produced from recycled plastics (including packaging and e.g. kitchen utensils), the Commission Regulation (EC) No 282/2008 of 27 March 2008 on recycled plastic materials and articles intended to come into contact with foods regulates the requirements for recycling processes. The EC keeps a register for validated FCM recycling processes (EC, 2019a). Mainly PET plastics are being recycled for FCM use. It should be noted that the recycling process itself is regulated, rather than regulating contaminating substances. Apart from FCMs, a large amount of recycled plastics (LD-PE, HD-PE, PP, PS) is downcycled into other non-FCM products, including waste bins, flower pots, outdoor furniture and others. Because skin-contact may occur at several occasions with these materials, such materials should also be safe to use. There is currently no comprehensive EU legislation in place that covers the chemical safety evaluation of recycled products, both thermoplastic and also thermoset materials. When it comes to textiles, both cellulose based and polymer based, there are several initiatives to explore the possibilities to recycling of these products into new textiles (as discussed in chapter 2). Currently also here a regulatory framework for safety evaluation of the recycled textiles is lacking, whereas this is urgently needed given the materialto-skin contact of these materials. If we anticipate that future technological developments enable a better recycling of plastics and textiles into FCMs, recycled plastic products and textiles, then a legislative framework will facilitate a large scale implementation of plastic and textile recycling strategies in a circular economy.

To iterate the contaminating substances that may end up in the recycled product, they may comprehend a wide diversity:

- Polymeric contaminants, i.e. polymeric impurities (monomers, oligomers, polymeric fractions) from a different polymer than the intended product;

- Additives (e.g. pigments, stabilizers, catalysts, fillers...);

- Chemical contaminants originating from previous use (odors and flavours, residues);

- Neo-formed chemical contaminants which are generated during the chemical or physical recycling process where heat, chemicals and/or pressure were applied in the process from collection, cleaning and reprocessing of the polymer;

- Contaminants (VOCs) originating from the degradation of polymers (Yamashita et al., 2009);

- Contaminants coming from the mixed collection of waste polymers (e.g. chlorinated and brominated substances and phthalates from plastics) (Yamashita et al., 2009). 
In the production of polymers and textiles, several substances are blended together to produce the intended polymer. These are called intentionally added substances (IAS). However, several nonintentionally added substances (NIAS) may occur in a recycled product, originating from the above mentioned contamination sources. Below, we will focus on testing methods for the detection of NIAS.

\subsection{Methods for (recycled) plastics and textiles}

The number of studies that designed methods specifically for analysis of contamination in recycled plastics is very limited. Only a small number of studies focussed on recycled polymers like PET, PVC, polyolefins and others. No studies were found on methods for contaminants in thermoset materials, for the reason that current thermoset materials are only recycled to a limited degree. For textiles no studies were identified that specifically focus on recycled materials. Because of specific methods for recycled polymers and textiles are limited or lacking, we discuss below methods that are used for nonrecycled (i.e. virgin) polymers and products thereof. The same holds for textiles. Concerning paper recycling, which has a long history already, many analytical studies on targeted and untargeted methods have been published, as recently reviewed by Peters et al. (2019). Whenever we deemed such methods complementary, we have included them in below discussion.

\subsection{Sample extraction and clean-up for NIAS in plastics}

The first step in NIAS analysis is the release of the analytes from the plastic or textile matrix. The extraction method to be chosen depends on the nature of the analyte; volatile analytes require a different approach than non-volatile analytes. Several extraction techniques can be employed for that purpose, which are discussed below. For plastics intended as FCM leaching experiments can be conducted in relevant food simulants (e.g. demineralised water, $3 \%$ acetic acid, olive oil and $10 \%$ and $50 \%$ ethanol). These simulants serve as extractant and act and collect that analytes of interest. Once the migration time is completed, the migrant will be further processed for determination of the analytes of interest. Regulation (EU) No 10/2011 provides directions on how to perform migration studies. This regulation also provides specific migration limits (SMLs) for a range of substances. Although this regulation applies to virgin plastics only, the listed substances may become a NIAS once the used plastics are being recycled. It's is therefore that these migration experiments may be very well suitable also for determination of NIAS in FCMs made of recycled plastics, although once again it should be noted that the mentioned SMLs only apply to virgin plastics. Specific technical approaches may apply, and technical guidelines for testing of e.g. kitchen utensils are provided at the European Reference Laboratory (EU-RL) for FCMs (EC, 2019b).

Above migration experiments are specifically designed for FCMs, but recycled polymers with other destinations require different extraction approaches. Several solvent extraction techniques have been employed to extract contaminants from recycled plastics. Vilaplana et al. (2007) extracted low molecular weight compounds (e.g. VOCs) from recycled high impact polystyrene (HIPS) using microwave assisted extraction (MAE) using a n-hexane/isopropanol mixture (50\%, v/v). Peters et al. (2019) recently reviewed the analytical approaches for identification of NIAS in paper and board FCM. Many of the sample preparation procedures discussed in that review can be applied for recycled matrices as well. These include liquid extraction approaches such as Soxhlet or other reflux extraction techniques, liquid solid extraction (LSE), ultrasound-assisted solvent extraction (UAE), often combined with some type of clean-up.

Volatile substances in recycled plastics may be extracted from the matrix using headspace, or a combination of headspace and solid phase microextraction (SPME), as demonstrated by Dutra et al. (2011) for volatile organic compounds (VOCs) in recycled PET and HDPE. They used this approach to evaluate the efficiency of VOC removal in the recycling process. Yamashita at al. (2009) used Tenax/Carboxen absorbent to capture VOCs from the waste plastic flakes, and used thermal-desorption (TD) coupled to GC-MS for determination. Ibarra et al. $(2018,2019)$ used purge and trap (volatiles) and acetonitrile extraction for the extraction of IAS and NIAS from films, laminates and PP FCMs. 


\subsection{Sample extraction and clean-up for NIAS in textiles}

Many studies towards contaminants in the textile industry focus on the pollution of the production facilities, and have investigated the effluents from these facilities. Only limited studies focused on the development of methods for contaminants in the textiles themselves. Luongo et al. (2014) developed an extraction method for the determination of quinoline derivatives in from polyester, cotton and mixed textile fibre materials using UAE with dichloromethane, combined with solid phase extraction (SPE) clean-up. Although in this study the analytes were not necessarily marked as NIAS, these methods will apply in a similar way when these analytes are unintentionally present in recycled textile fibres. Avagyan et al. (2014) extracted benzothiazoles and benzotriazoles from textiles by UAE with a $20 \%$ acetone in DCM mixture. Detection of NIAS may also be feasible directly, using direct techniques that do not require extraction of the NIAS from the matrix. Those techniques detect the contaminants at the surface of the material, without the need for extraction, and can be applied as screening techniques. These will be discussed below in more detail.

\subsection{Targeted methods detection}

A range of methods have been reported for targeted analysis of substances, mostly based on chromatography combined with MS approaches. Various ionisation approaches are applied like electron impact (EI) for GC-MS and electrospray ionisation (ESI) for LC-MS/MS. Quadrupole and triple quadrupole approaches are most often applied as mass analysers, but the use of other analysers was also reported. Volatile and apolar substances are amenable to gas chromatography (GC). Garcia Ibarra et al. (2018, 2019) produced a list of intentionally added substances (IAS) and nonintentionally added substances (NIAS) (alkanes, aldehydes, alcohols, phthalates, citrates, adipates, phosphates, phenolic substances, diisocyanates, and fatty acids) in plastic packaging materials that were identified with GC in combination with single quadrupole MS. GC-MS was used by Dutra et al. (2011) and Yamashita et al. (2009) for the detection of VOCs, styrene trimers and aliphatics. Vilaplana et al. (2007) used GC-time of flight (ToF)-MS for the detection of contaminants in recycled and virgin HIPS.

Only a few studies investigated substances in textiles or fabrics, and most of them focussed on derivatives from AZO dyes because of their (suspected) negative health effects. Luongo et al. (2014, 2016) and Avagyan et al. (2014) used GC-MS for the determination of aromatic anilines and derivatives, quinolines, benzothiazoles and benzotriazoles in textile. Brüschweiler et al. (2014) investigated derivatives from AZO dyes (aromatic amines) in textile products using LC-ESI ${ }^{(+/-)}$-MS/MS. Abdallah et al. (2017) investigated BFRs in polyester textiles. Their detection methods were GC-MS for PBDEs, and LC-ESI(-)MS/MS for the separation and detection of HBCDD diastereomers in these samples.

\subsection{Comprehensive suspect screening and non-target analysis}

The studies on the identification of NIAS by MS approaches shows various levels of complexity, particularly on the methods used for identification. Fairly straightforward approaches involve the identification using a NIST library. Somewhat more complicated is the use of external databases such as SciFinder and Chemspider, or the use of a suspect list. The highest complexity is achieved when, with an exact mass as a starting point, substantial efforts are made to unravel the molecular composition of a NIAS, ultimately leading to a successful identification of the unknown substance. With the increasing level of complexity, the complexity of applied instrumentation and identification approach increase as well. Below, we will discuss examples of different approaches. As noted before, there are only limited studies on the investigation of recycled polymers, except for FCMs where some studies on recycling of polymers were reported. 
Song et al. (2019) investigated NIAS markers that were discriminative towards recycled EPS versus virgin EPS. They employed HS-SPME-GC-MS for the analysis of VOCs, and used the NIST library for identification purposes, resulting in 99 identified substances, of which 17 substances (o-xylene, acetophenone, ethylbenzene, a-ethylstyrene, 2-phenylpropenal, propylbenzene, 2-phenyl-1-propene, undecanal, benzoic acid ethyl ester, 2ethyl-1-hexanol, decanal, benzylcarboxaldehyde, isopropylbenzene, 2,4-diphenyl-1-butene, dodecanal, benzaldehyde, nonanal) were discriminative towards recycled EPS.

Martinez-Bueno et al. (2019) recently reviewed the use of high resolution accurate mass spectrometry (HRAMS) strategies for the identification of migrating substances (IAS and NIAS) in food contact materials. They identified 17 studies that applied HRAMS, mostly coupled to LC for this purpose, showing that the application of HRAMS is still in its infancy for studying migrants. The applied MS instruments were Q-ToF-MS and Q-OrbitrapMS interfaced to LC with ESI+ and ESI-. Only a small number of GC applications were reported using EI or APCI sources, connecting to above instruments. Several data acquisition strategies were reported, including Data Independent Acquisition (DIA) - full scan MS, DIA - all ion MS/MS, Data Dependent Acquisition (DDA) - Full MS-ddMS ${ }^{2}$ and full scan MS. In DDA mode, the instrument performs the data collection using predetermined rules, switching between full-spectrum MS survey and a full-spectrum product ion (MS/MS) analysis dependent mode, in one chromatographic run. The switching is automatically controlled based on the predetermined rules: based on the intensity of the precursor ions observed; or based on other criteria such as isotope pattern, charge state or specific $\mathrm{m} / \mathrm{z}$ values on an inclusion list or an exclusion list. In DIA, all ions within a selected $\mathrm{m} / \mathrm{z}$ range (e.g. 50-150) are fragmented and analysed in a second stage of tandem MS. The switching between MS and MS/MS is automatically performed to obtain fragments for all precursor ions present. MS and MS/MS data of unknown substances are also acquired simultaneously in one chromatographic run. The DIA mode has significant advantages in identifying unknown substances compared with other acquisition methods, because no exclusion of peaks occur based on the predetermined criteria. In all ion fragmentation (AIF), MS/MS experiments can be performed at a low and higher collision energy, resulting in different fragmentation, and, when combined, in richer MS/MS spectra. This approach typically results in large number of hits (i.e. detected masses), and not all of them may be relevant. In two recent studies (Canellas et al., 2019; Vera et al., 2019), the use of ion mobility MS (IMS) was presented as a way to reduce background noise during acquisition, through drift-time alignment. Through this process, they demonstrated that matrix-interferences can be reduced substantially, leading to cleaner spectra. The next step after data acquisition is the reduction of the obtained 1000's of masses down to an appreciable number. This data reduction can be done on the basis of mass range, signal-to-noise threshold level, a minimum response threshold, PCA analysis of two or multiple samples, visual comparison to blank or reference sample and peak deconvolution. This should preferably result in a limited number of hits that will proceed to the next stage: the (tentative) identification of the peaks. The identification is done by the following procedures, or (often) combinations thereof: study of the fragmentation pattern, comparing fragmentation to in-silico fragmentation tools, confirmation by pure standards (when available), comparison to databases (e.g. Chemspider, SciFinder), comparison to mass spectral databases (NIST, MassBank or mzCloud), studying isotope pattern, reducing mass tolerance, bibliographic search and background knowledge. 


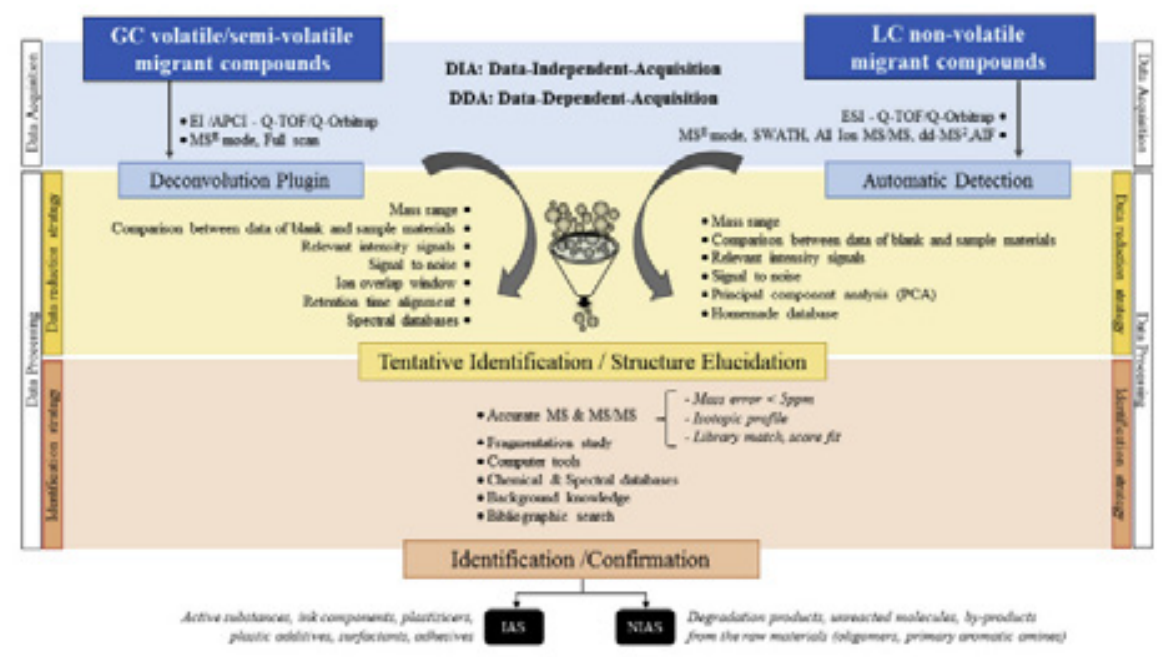

Figure 2 Schematic overview of the workflow for non-targeted identification of IAS and NIAS using HRAMS approaches. Figure taken from Martinez et al. (2019).

Below, two examples are presented of studies where (tentative) identification was performed on substances in FCMs. LC-ESI-Q-TOF-HRAMS was applied by Ramos et al. (2019) for the identification of migrants from multilayer FCM. They operated the instrument at 32.000 resolution FWHM, and applied a data-independent data-acquisition (DIA) mode (SWATH; Sequential Windowed Acquisition of All Theoretical MS). They obtained 3149 possibilities (unique masses), and reduced this number substantially by filtering strategies like selecting the most intense peaks only, through which they arrived ultimately at 21 possibilities that were in-depth investigated. The latter was done by in-silico fragmentation prediction, experimental fragmentation studies, search in MS databases (Metlin, MassBank, mzCloud) and bibliographic search. Through this approach, 26 substances were (tentatively) identified. Most substances were cyclic oligomers originating from PU adhesives. Some cyclic oligomers were reported for the first time in this study. A confirmation of some of the tentatively identified structures was not possible, because of the lack of standards, according to the Schymanski rules (see below). Martinez-Bueno et al. (2017) investigated NIAS from a nanofilm FCM by using LCQ-Orbitrap-HRAMS, operated in the All Ion Fragmentation (AIF) mode, identifying the substances through a process of data reduction (e.g. intensity threshold, relative intensity, principle component analysis), followed by comparison of the fragments of each substance with a mass spectral library. Through this approach, the 4 NIAS were tentatively identified (N,N-diethyldodecanamide, N-[(9Z)-9Octadecen-1-yl]acetamide, 1-Palmitoylglycerol and Glycerol stearate). For GC-Q-Orbitrap-HRMS, they compared their fragments with the available NIST library, resulting in the identification of 3 additional substances (tripropylene glycol diacrylate, 10-Heneicosene and a-Tocopherol acetate).

Once a substance has been (tentatively) identified, it can be included in a home-made database for future reference. Samples analysed at later stage can be compared to the substances in this list, which facilitates and accelerates the identification process. This process is called ' suspect screening', and comprises the screening of sample extracts making use of lists with substances that have previously been identified or reported. Such lists ideally contain the name of the substance, possible synonyms, IUPAC name, identifiers (e.g. CAS number, EINECS number), chemical formula, exact mass and the nature of the identified substance (e.g. $[\mathrm{M}+\mathrm{H}]^{+},[\mathrm{M}+\mathrm{Na}]^{+}$). Such lists can be generated by a single lab, or by multiple laboratories together on a shared platform. An example of these is the lists in the high resolution mass spectral database generated by the Norman network in the field of environmental pollution (http://massbank.eu/MassBank/).

During the (tentative) identification process, the criteria defined by Schymanski et al. (2014) can be used to indicate the confidence at which a substance is identified. These criteria originate from the environmental research field, but can be applied to any HRAMS identification process. These criteria are used to ease communication on the status of identification. Schymanski identified five levels of confidence. An increasing confidence in identification is supported by an increasing effort on the identification, as indicated in Table 1. The ultimate identification is achieved at level 1 , where the 
confirmation is obtained through measurement of a pure standard. In most cases however, the identification will finish at level 2 or 3 , because of the lack of a pure standard.

Table 1 Confidence levels defined by Schymanski et al. (2014).

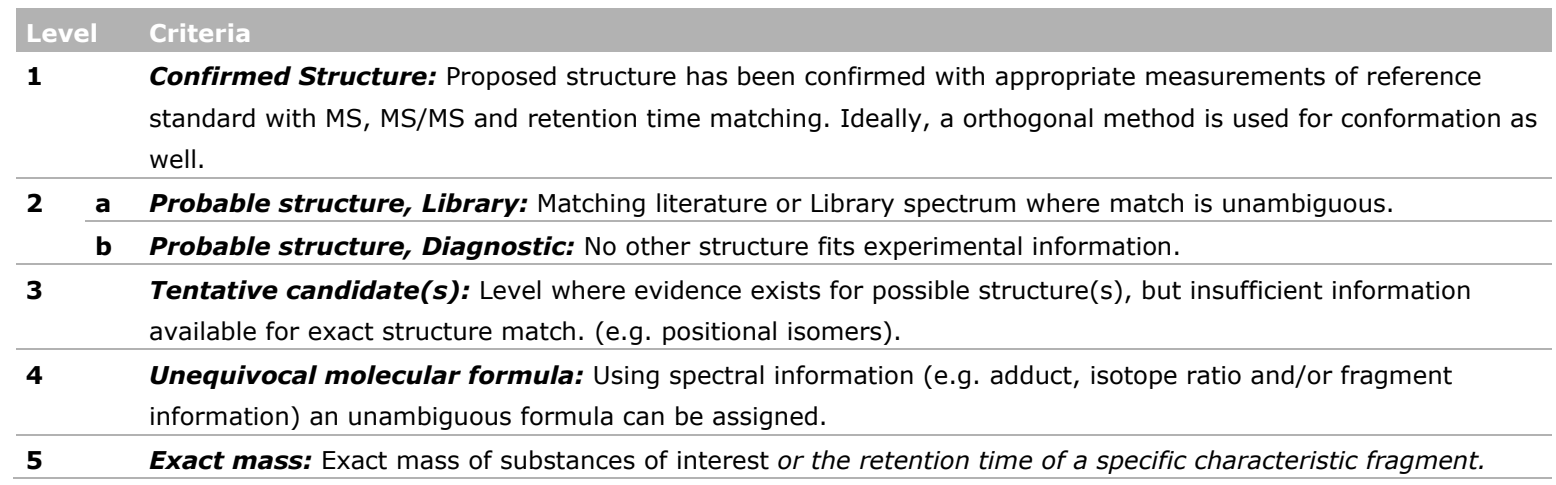

A framework for quantification of unknown substances, applied for paper packaging but also amenable for plastics, was developed by Pieke et al. (2017).

\subsection{Instrumental (surface ionisation) screening techniques}

Detection of NIAS may also be feasible directly, using direct techniques that do not require extraction of the NIAS from the matrix. Those techniques detect the contaminants at the surface of the material, without the need for extraction, and can be applied as screening techniques. A prerequisite for such techniques is that the contaminants can be released easily from the plastic/textile matrix without solvent transfer. Although such techniques potentially enable the direct (qualitative) characterisation of NIAS, no studies were found that applied such technologies.

\subsection{Combining chemical analysis and bioassays}

Complete information on which substances are in fact present in (recycled) plastics or textiles is, however, not possible to obtain: during the production and/or recycling of plastic and textile articles, side products are formed that can remain in the finished product. These NIAS are sometimes well characterized, but a full elucidation of all NIAS present in (recycled) plastics and textiles is currently neither technically nor economically feasible. Thus, recycled plastics and textiles may contain unknown substances that cannot be quantified or characterized in terms of their specific toxicity. As a consequence, the only way to assess if a plastic or textile transfers substances of concern into foods and/or the environment is to test overall migrant toxicity through the use of bioassays.

Bengtström et al. (2014) completed a study on an interdisciplinary strategy for the screening and identification of substances with potential adverse health effects in food packaging materials. A comprehensive extraction process, compatible with both chemical and toxicological analysis, was developed, which consisted of a purge-and-trap method for small volatile organic substances, and a boiling ethanol reflux system for semi- and non-volatile substances. The first step in this method is to test the FCM extracts for endocrine disruptive effects, genotoxicity, and metabolic effects of xenobiotics by in-vitro effect assays. The response from the Aryl Hydrocarbon Receptor (AhR) assay can be linked to these metabolic effects. Samples that are tested positive for these toxicity tests, are then subjected to an effect directed analysis (EDA) scheme (Figure 3). 


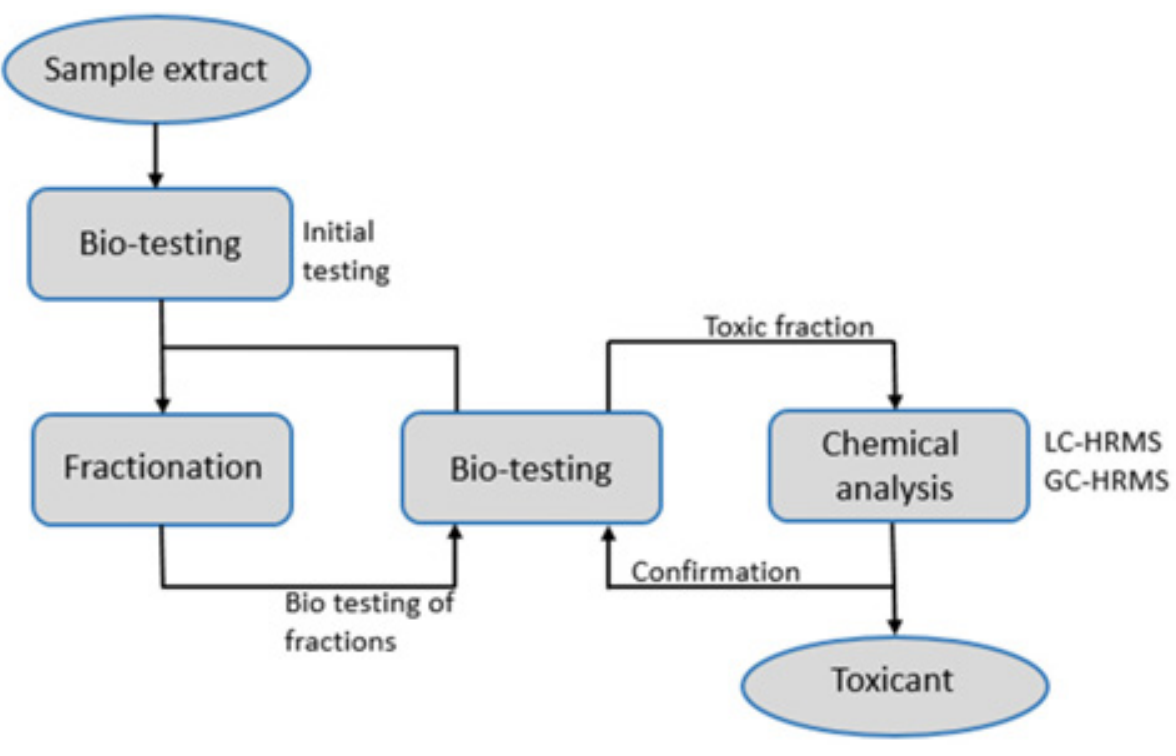

Figure 3 Effect-directed analysis (EDA) scheme for the identification of substances that exhibit an effect in a bioassay. Taken from Peters et al. (2019).

The aim of this approach is to narrow down the substances that potentially caused the response in the assay, and ultimately to identify the responsible substance causing the response. In this scheme a positive extract is fractionated by HPLC (e.g. on a C18 column along the polarity axis) and results in multiple fractions, and subjected to a second screening of cell assays. Specific fractions exhibited a response in the cell-assay, and directed towards the responsible bioactive substance. Secondly, the positive fractions were analysed by GC-QTOF-MS and UHPLC-QTOF-MS for identification of the bioactive substances. They faced problems with the availability of libraries for the UHPLC-QTOF-MS data, thus a large part of the tentative identification had to be performed manually, whereas the identification for the GC-QTOF-MS data could by automated. Following these difficulties, Bengtström created an accurate mass database containing about 2100 substances with reported use in paper and board, and which can be found in their report. The first step of tentative identification was a fully automated step of integration and deconvolution. Then, the quasi-molecular ions $\left([\mathrm{M}+\mathrm{H}]^{+}\right.$or $\left.[\mathrm{M}-\mathrm{H}]^{-}\right)$ were located. The vendor specific software was used to find many suggestions for molecular formulas of a single $\mathrm{m} / \mathrm{z}$ in the spectra, after which the isotope distribution was used to select the most matching one. They concluded that both isotope distribution and hits in the accurate mass database greatly increased the possibility of a correct tentative identification. In this study, the combination of bioassays with chemical analysis resulted in the identification of substances with endocrine disruptive effects, effects on the metabolism of xenobiotics, and mutagenic effects. Also, the concentration of the substances found in the extracts by chemical analysis, was successfully correlated in two of the three bioassays with the originally measured toxicological effect, thus proving the value of this combination.

In the area of environmental research, the fractionation part in EDA approaches was recently further innovated. Zwart et al. (2018) couples UPLC fractionation to a 384 wells fraction collector, allowing for 192 fractions without replicates (collected at 9 seconds interval), or a smaller number with replicates. The small sample volumes were applied to a agonistic and antagonistic androgen and estrogen receptor activity assay. Jonker et al. (2017) applied gas chromatographic (GC) fractionation of volatiles. The eluent of the GC column was diverted through a Y-splitter to the MS and to a the fraction collector. On the way to that fraction collector, the flow was directed to an inverted Y-piece where vaporized trap solvent is infused. The latter flow is directed outside the GC oven allowing subsequent condensation and stepwise collection of liquid fractions with trapped analytes on a 384-well plate for further application to assays.

Veyrand et al. (2017) performed a migration study on a plastic cup suspected to release the endocrine active substance 4-nonylphenol (4NP). The ethanol FCM extracts were divided into two parts, one for analytical and one for toxicological analysis. Chemical analysis of non-volatiles was performed by GCMS for in full scan mode. Whereas LC-MS/MS was used for a targeted analysis on TNPP and 4NP, using 
APCI for TNPP and ESI for 4NP. The ERa-CALUX and AR-CALUX assays were used for in vitro toxicological analysis. The leaching of 4NP was confirmed by LC-MS/MS and GC-MS together with a positive response in the bioassays, which meant an increase in both estrogenic and anti-androgenic activities. This study proves again how bioassays can give additional information to strengthen the results obtained from chemical analysis. Van Leeuwen et al. (2019) evaluated the in vitro (anti)estrogenic and (anti)androgenic potencies of a large number of BPA analogues (including BPS) and BADGE and BFDGE analogues and metabolites. They analysed a selection of drinking bottles and found traces of BPA and BPS.

Bradley et al. (2008) tested nineteen food contact materials according to a short-term test battery of in vitro bioassays developed by the Biosafepaper EU project, and combined this with detailed chemical characterisation by GC-MS. While these were paper and cardboard samples the method will work equally well for plastic and textile samples. The samples intended to be in contact with moist or wet foods were extracted with water, ethanol was used for paper and board holding fatty foods, and Tenax was used as a simulant for dry foods. Ethanol was used to extract the migrants from the Tenax for further testing by in vitro toxicity assays, as described by the Biosafepaper project (Groh et al., 2017). The water extracts were evaporated to dryness and the residue was redissolved in dry acetone, which was then derivatised by adding the silylation reagent $\mathrm{N}, \mathrm{O}$-bis(trimethylsilyl)trifluoroacetamide (BSTFA). After another evaporation step, the residue was redissolved in dichloromethane and analysed by GC-MS, with EI and run in full scan mode $(50-600 \mathrm{~m} / \mathrm{z})$. The ethanol extracts were analysed both with and without silylation. The derivatised extract was evaporated to dryness and redissolved in acetone before injection, with the same configurations for the MS, but scanned a mass range from $40-450 \mathrm{~m} / \mathrm{z}$. The ethanol extracts from the exposed Tenax were treated and analysed according to the same protocol as the regular ethanol extracts. Then, all extracts were subjected to the following cytotoxicity assays: total phenolic content (TPC) with HEp-2 and Hepa-1c1c7, the RNA synthesis inhibition test, and the inhibition of boar spermatozoan motility. The Ames test and the Comet assay were used to assess genotoxicity. Eventually, none of the water or Tenax extracts tested positive for cyto- or genotoxicity, however, all ethanol extracts responded positive to the cytotoxicity assays to some extent. Unfortunately, Bradley et al. (2008) could not assign the responses to any specific substance, although there seemed to be a correlation between the total amount of migrants and the degree of toxicity.

\subsection{Safety assessment frameworks}

The combination of bioassays with chemical analysis has shown to be very effective, although a chemical identification is necessary before toxicity can be linked to a substance. The threshold of toxicological concern (TTC) concept has been adopted within the European Union legislation as a tool to deal with unknown chemical substances (EFSA and WHO, 2016). The TTC concept uses tentative exposure data to determine whether intake of a substance is below an acceptable threshold of no concern, defined by assigning a Cramer class based on the chemical structure or so-called structural alerts. TTC is a preliminary assessment tool that has been applied in strategies to detect and evaluate NIAS as described by Koster et al. (2014) and Pieke et al. (2018a).

Koster et al. published an extensive report on a safety assessment strategy for detecting unknown NIAS in FCMs. The strategy enables one to distinguish toxicologically relevant from toxicologically less relevant substances by several toxicological assessments. The method is described as a complex mixture safety assessment strategy (COMSAS), and uses several analytical and biological screening procedures that allow the exposure to NIAS to be estimated (Koster et al., 2015). CoMSAS is a decision tree method based on the TTC concept, and was applied by Koster et al. to 3 carton FCMs. The LOD of $10 \mu \mathrm{g} / \mathrm{kg}$ food, that is generally required and used for the detection of migrants in FCMs, has been replaced by an exposure threshold of $90 \mu \mathrm{g} /$ day, based on the TTC of Cramer toxicity class III substances. The new threshold is increased by nine times, which substantially reduces the group of components that must be identified. The identification of unknown substances is focussed only on those substances exceeding the threshold. 
Step 2. Exclude presence of dioxins, heavy metals and other highly toxic or TTC excluded classes of substances

Step 3. Exclude presence of structural alerts for genotoxicity or a genotoxic effect of a migration extract

Step 4. Substance specific risk assessment of substances exceeding the exposure threshold of $90 \mu \mathrm{g} / \mathrm{day}$ and of substances detected in step $1 / 2 / 3$

Step 5. Exclude allergenic effects based on literature data and/or targeted methods for known allergens

Figure 4 Complex mixtures safety assessment strategy (CoMSAS) (Koster et al., 2014).

The first step of the chemical analysis consists of a screening of substances in the migrate extract that exceed the exposure threshold of $90 \mu \mathrm{g} /$ day, based on the TTC for Cramer class III substances. The analytical screening combines four different analytical techniques to ensure as many NIAS as possible are detected. The present evaluation includes (1) headspace GC-MS (EI) for volatile substances, (2) GC-MS (EI) for semi-volatile substances, (3) derivatisation of non-volatiles followed by GC-MS (EI) analysis, and (4) LC coupled to an evaporative light scattering detector (UV/ELSD) for analysis of nonvolatiles. Since it is almost impossible to incorporate chemical standards, due to the large number of potentially present substances, detectors are used that give a uniform response so that a semiquantitative estimate of the migration can be made. Whenever in LC-ELDS analysis a substance exceeds the threshold of $90 \mu \mathrm{g} / \mathrm{day}$, it will be identified by GC- and LC-MS. After the analytical screening, an exclusion of known highly toxic substances and substances that are excluded from the $\pi \mathrm{C}$ concept was performed as the second step. The presence of the following substances was examined: aflatoxin-like substances, $\mathrm{N}$-nitroso substances, azoxy substances, polyhalogenated dibenzo-p-dioxins, -dibenzofurans and -biphenyls, steroids, non-essential metals, high molecular weight substances, and organophosphates and carbamates. The third step includes a genotoxicity assessment of the migration extract by means of a bioassay. The BlueScreen HC assay was chosen because of its sensitivity for gene mutations, clastogenicity and aneugenicity. When the bioassay presents a negative response, it can be assumed that there are no genotoxic substances present and further identification of substances is not required. When the bioassay does give a positive response for genotoxicity, additional work must be performed to identify the substance(s). Identification is then done by fractionation of the extract by size-exclusion chromatography (SEC), which results in a limited amount of substances per fraction, after which the fractions are submitted to a second bioassay. The fraction that then give a positive response for genotoxicity is further analysed. According to Leeman et al. (2015), the CoMSAS approach is the only one of its kind to assess unidentifiable NIAS until now. The introduction of an exposure threshold provides a pragmatic way for efficient screening for toxicological relevant NIAS in paper and board FCMs and reduces the effort the analytical chemist and toxicologist have to make in the whole process.

Another approach is proposed by Pieke et al. (2018a). They realized that a risk assessment of NIAS is most of the time not possible since much information is missing. This was also concluded by Muncke et al. (2017). Most NIAS do not have assigned chemical structures, concentration data or characterization of hazards. In a recent series of publications Pieke et al. (2017, 2018a, 2018b) described the use of explorative methods to determine NIAS in food contact materials and concluded that untargeted analytical strategies are useful to estimate the concentration and chemical structure of NIAS. However, a comprehensive analysis of all substances found via exploration is not realistic and therefore a risk prioritization is required to identify the substances that most likely have adverse health effects. 
During the last years, in silico methods have received substantial attention which stimulated their development and made them become more interesting for the assessment of chemical hazards. In silico tools are essentially computer models, able to make predictions for a non-evaluated substance based on knowledge extracted from a collection of structurally related substances with experimental toxicity data. Quantitative structure-activity relationship (QSAR) modelling of chemical hazard may provide substitute toxicity data if testing is prohibitive, which has successfully been applied to FCM for hazard-based assessment and prioritization by Van Bossuyt et al. (2017) and by Pieke et al. (2018a). The widespread use of in silico tools, however, remains limited due to the non-flexibility of the current regulatory framework and the fact that uncertainty exists as to which in silico model is most suitable to assess a given substance for a particular endpoint. Therefore, the most promising application of in silico tools will be its use in priority setting upon screening of a large number of substances. A detailed characterisation of the complete toxicological profile of all substances in a non-targeted chemical analysis is not feasible from an economic and ethical (animal testing) point of view. By identifying substances of highest concern, the resources available for experimental testing can be attributed in a more efficient way. 


\section{Conclusions}

The instalment of a circular economy will contribute to an increase in the recycling of plastics and textiles. The successful recycling of plastics and textiles depends, apart from technical aspects, to a large degree on the safety of the products resulting from recycling. The safety of recycled products is a prerequisite for societal acceptance of recycled plastics and textiles. The transition to a circular economy of plastics and textiles will not be accomplished if no guaranteed safe products can be delivered to the market. The evaluation of the safety of recycled plastics and textiles is crucial, but a framework for evaluation of potential hazardous substances and associated risks for the consumer is virtually absent. More specifically, a legislative framework, risk assessment framework, and relevant testing strategies are urgently needed.

In this report the recycling and reprocessing of thermoplastic materials, composites and textiles have been described, based on a (scientific) literature survey. In the production of plastics and textiles many substances are used, and several of these are highly hazardous and therefore of significant concern. During the recycling process or the use of recycled materials these substances may be released to products or the environment, and recycling workers and consumers can be exposed to these substances. A number of 238 hazardous substances associated with plastics and 43 classes of hazardous substances associated with textiles have been identified in this report. Plastics may also be a source of contamination in the recycling process if they are (accidently) mixed with other plastics and well known plastic additives as phthalates and brominated flame retardants have been found in children toys and food contact materials produced from recycled plastics. Since composites are rarely recycled no information was found about contaminations in recycled composite material. For textiles there is only very limited information on hazardous substances for recycling and recycled end products. However, synthetic textile fibres like polyester and nylon can end up acting as chemical pollutants as well as substrates that magnify the accumulation of other harmful substances in the environment.

For the analysis of (hazardous) substances or NIAS in recycled plastics or textiles two strategies are applied: targeted analytical methods for the analysis of predicted and known substances, and untargeted or screening methods to analyse unknown substances. Targeted analysis are performed using GC-MS based methods for volatile substances and GC- and LC-MS based methods for semi- and non-volatile substances. For the identification of the targeted substances dedicated substance libraries are used. Untargeted analysis is performed to identify as many as possible substances in a migrate or extract, especially substances that cannot be predicted beforehand, which makes it a challenging task. This type of analysis is mostly done using GC and LC techniques in combination with high resolution mass spectrometry techniques like Q-Orbitrap or Q-TOF mass spectrometry. These high resolution accurate mass spectrometers are favoured because of the complexity of the sample extracts and are operated in various data acquisition modes (e.g. full scan, data-dependent acquisition) for untargeted analysis. Often software is used to generate elemental formulas for the accurate masses of the detected substance peaks, and identification is generally done with the help of substance libraries and databases.

In untargeted analysis in silico tools are gaining importance in the identification of substances. Recent publications describe the use of so-called explorative methods, an untargeted analytical strategy to estimate the concentration and chemical structure of unknowns. However, a comprehensive analysis of all substances found via exploration is not realistic and therefore a risk prioritization is required to identify the substances that most likely have adverse health effects. The combination of bioassays with sensitive analytical techniques, effect directed analysis, seems to be the most promising and efficient way of identifying NIAS and their hazard to human exposure. In vitro bioassay based testing allows for a rapid evaluation of multiple toxicological endpoints. In addition it allows the determination of a combined effect of all detected substances, including the unknowns, in a sample. Positive sample extracts or fractions thereof can be further analysed with GC- or LC-HRMS techniques to identify the 
toxic substances. Future research is required into the selection of the bioassay. CoMSAS is an example of a successful approach for the detection and identification of unknown substances in complex samples. It combines the sensitivity of analytical techniques with the ability of testing for cytotoxicity, genotoxicity and endocrine disruptors in one method. The number of analytes that have to be identified is reduced by using a threshold based on the relevant TTC instead of using the generic migration limit or LOD of $10 \mu \mathrm{g} / \mathrm{kg}$ food. By identifying substances of highest concern, the resources available for experimental testing can be attributed in a more efficient way.

For a successful implementation of safe recycling processes and recycled products, there is an urgent need for comprehensive approaches for identification and quantification of hazardous substances, and to assess their safety. The first step in this process is method development for the identification and quantification of hazardous substances in recycled plastics and textiles. Currently such methods are virtually absent, especially for textiles. The literature review has revealed that targeted and untargeted mass spectrometric methods are needed. However, since many of the substances detected in such analyses may be NIAS or otherwise unknowns, identification is a difficult and time-consuming process. For efficient identification such techniques have to be combined with compound databases that may be compiled from different sources. Since it is unlikely that all detected substances can be identified an effect-directed method would be very helpful to detect and finally identify potentially hazardous substances. However, as with the other analytical techniques, effect-directed analysis and especially the coupling of the bio-assay and the instrumental technique is not standard and has to be developed. Finally, risk prioritization schemes and techniques as TTC and CoMSAS for risk assessment have not been used for recycled plastic and textile materials and therefore it is strongly advised to develop these schemes and techniques for this new playing field. 


\section{References}

Abdallah MAE, Drage DS, Sharkey M, Berresheim H, Harrad S (2017). A rapid method for the determination of brominated flame retardant concentrations in plastics and textiles entering the waste stream. Journal of separation science, 40, 3873-3881.

Achilias DS, Andriotis L, Koutsidis IA, Louka DA, Nianias NP, Siafaka P, Tsagkalias I, Tsintzou G (2012). Recent Advances in the Chemical Recycling of Polymers (PP, PS, LDPE, HDPE, PVC, PC, Nylon, PMMA) in Material Recycling - Trends and Perspectives.

http://cdn.intechopen.com/pdfs/32560/InTech-

Recent_advances_in_the_chemical_recycling_of_polymers_pp_ps_ldpe_hdpe_pvc_pc_nylon_pmm a_.pdf.

Aguado J, Serrano D (2007). Feedstock Recycling of Plastic Wastes, Cambridge: Royal Society of Chemistry.

Al-Salem SM, Antelava A, Constantinou A, Manos G, Dutta A (2017). A review on thermal and catalytic pyrolysis of plastic solid waste. Journal of Environmental Management, 197, 177-198.

Ambrose CA, Hooper R, Potter AK, Singh M (2002). Diversion from landfill: Quality products from valuable plastics. Resources, conservation and recycling, 36, 309-318.

ASTM (2000). ASTM Standard D5033. Standard guide to development of ASTM Standards relating to recycling and use of recycled plastics. ASTM International, West Conshohocken, PA, http://dx.doi.org/10.1520/D5033-00.

Avagyan R, Luongo G, Thorsén G, Ostman C (2014). Benzothiazole, benzotriazole, and their derivates in clothing textiles-a potential source of environmental pollutants and human exposure.

Environmental science and pollution research international, 22, 5842-5849, doi: 10.1007/s11356014-3691-0.

Bayer FL (2002). Polyethylene terephthalate recycling for food-contact applications: testing, safety and technologies: a global perspective. Food Addit. Contam., 19, 111-134.

Behrendt G, Naber BW (2009). The chemical recycling of polyurethanes (review). Journal of the University of Chemical Technology and Metallurgy, 44, 3-23.

Bengtström L, Trier X, Granby K, Rosenmai AK, Petersen JH, (2014). Fractionation of extracts from paper and board food contact materials for in vitro screening of toxicity. Food Additives \& Contaminants: Part A, 31, 1291-1300.

Bernardeau F, Perrin D, Caro AS, Benezet JC, Ienny P (2018). Development of a recycling solution for waste thermoset material: waste source study, comminution scheme and filler characterization. Journal of Material Cycles and Waste Management, 20, 1320-1336.

Birnbaum LS, Staskal DF (2004). Brominated flame retardants: cause for concern?, Environ. Health Perspect., 112, 9-17.

Bradley EL, Honkalampi-Hamalainen U, Weber A, Andersson MA, Bertaud F, Castle L, Dahlman O, Hakulinen P, Hoornstra D, Lhuguenot JC, (2008). The BIOSAFEPAPER project for in vitro toxicity assessments: Preparation, detailed chemical characterisation and testing of extracts from paper and board samples, Food and Chemical Toxicology, 46, 2498-2509.

Browne MA, Crump P, Niven SJ, Teuten EL, Tonkin A, Galloway T, Thompson RC (2011). Accumulation of microplastic on shorelines worldwide: Sources and sink. Environ. Sci. Technol., 45, 9175-9179.

Brüschweiler BJ, Küng S, Bürgi D, Muralt L, Nyfeler E (2014). Identification of non-regulated aromatic amines of toxicological concern which can be cleaved from azo dyes used in clothing textiles. Regulatory Toxicology and Pharmacology, 69, 263-272.

Camacho W, Karlsson S (2000). Quality-determination of recycled plastic packaging waste by identification of contaminants by GC/MS after microwave assisted extraction (MAE). Polym. Degrad. Stabil., 71, 123-134.

Canellas E, Vera P, Nerín C, (2019). Ion mobility quadrupole time-of-flight mass spectrometry for the identification of non-intentionally added substances in UV varnishes applied on food contact materials. A safety by design study. Talanta 205, 120103. 
Chen SJ, Ma YJ, Wang J, Tian M, Luo XJ, Mai BX (2009). Brominated flame retardants in children's toys: concentration, composition, and children's exposure and risk assessment. Environ. Sci. Technol., 43, 4200-4206.

De Carvalho GM, Muniz EC, Rubira AF (2006). Hydrolysis of post-consume poly (ethylene terephthalate) with sulfuric acid and product characterization by WAXD, 13 C-NMR and DSC. Polym. Degrad. Stab., 91, 1326-1332.

Dutra C, Pezo D, Freire MTdA, Nerín C, Reyes FGR (2011). Determination of volatile organic compounds in recycled polyethylene terephthalate and high-density polyethylene by headspace solid phase microextraction gas chromatography mass spectrometry to evaluate the efficiency of recycling processes. Journal of Chromatography $A_{\perp} 1218,1319-1330$.

Dutra C. Freire MT, Nerín C, Bentayeb K, Rodriguez-Lafuente A, Aznar M, Reyes FGR (2014). J. Braz. Chem. Soc., 25, 686-696. Migration of Residual Nonvolatile and Inorganic Compounds from Recycled Post- Consumer PET and HDPE. http://dx.doi.org/10.5935/0103-5053.20140016.

EC (2011). Commission Regulation (EU) No 10/2011 of 14 January 2011 on plastic materials and articles intended to come into contact with food. http://eur-lex. europa.eu/legalcontent/EN/ALL/?qid1/41511423737824\&uri1/4CELEX: 32011R0010. (Accessed 23 November 2017).

EC (2019a). https://ec.europa.eu/food/sites/food/files/safety/docs/cs_fcm_legis_recyclingprocesses_applications.pdf

EC (2019b). https://ec.europa.eu/jrc/en/eurl/food-contact-materials/technical-guidelines

EFSA/WHO (2016). Review of the threshold of toxicological concern (TTC) approach and development of a new TTC decision tree. EFSA Support. Publ. 2016 EN-1006 1-50. https://doi.org/10.2903/SP.EFSA.2016.EN-1006.

Ellen McArthur Foundation (2017a). The new plastics economy: Rethinking the future of plastics \& catalysing action. https://www.ellenmacarthurfoundation.org/publications/the-new-plasticseconomy-rethinking-the-future-of-plastics-catalysing-action

Ellen McArthur Foundation and Circular Fibres Initiative (2017b). "A New Textiles Economy: Redesigning Fashion's Future".

Eriksen MK, Pivnenko K, Olsson ME, Astrup TF (2018). Contamination in plastic recycling: Influence of metals on the quality of reprocessed plastic. Waste Management 79, 595-606.

EU (2015). Commission delegated directive (EU) 2015/863 of 31 March 2015 amending Annex II to Directive 2011/65/EU of the European Parliament and of the Council as regards the list of restricted substances, Off. J. Eur. Union. L137, 10-12.

Euromonitor International Apparel \& Footwear (2016). "Global fashion industry statistics International apparel," Fashion United. https://fashionunited.com/global-fashion-industrystatistics.

Eurostat (2017). Packaging waste statistics. http://ec.europa.eu/eurostat/statisticsexplained/index.php/Packaging_waste_statistics.

G. Arthur (2017). Facts you should know about recycled polyester, Suston Magazine, Norr Agency, 5 June 2017. http://sustonmagazine.com/2017/06/05/facts-you-should-know-about-recycledpolyester/.

Garcia-Ibarra VC, Rodriguez Bernaldo de Quiros A, Paseiro Losada, P, Sendon R (2018). Identification of intentionally and non-intentionally added substances in plastic packaging materials and their migration into food products. Anal. Bioanal. Chem., 410, 3789-3803.

Garcia-Ibarra VC, Rodriguez Bernaldo de Quiros A, Paseiro Losada, P, Sendon R (2019). Non-target analysis of intentionally and non-intentionally added substances from plastic packaging materials and their migration into food simulants. Food Packaging and Shelf Life, 21, 100325.

Geyer B, Lorenz G, Kandelbauer A (2016). Recycling of poly(ethylene terephthalate) - A review focusing on chemical methods. Express Polym. Lett, 10, 559-586.

Gómez Ramos MJ, Lozano A, Fernández-Alba AR, (2019). High-resolution mass spectrometry with data independent acquisition for the comprehensive non-targeted analysis of migrating chemicals coming from multilayer plastic packaging materials used for fruit purée and juice. Talanta 191, 180-192.

Groh KJ, Backhaus T, Carney-Almroth B, Geueke B, Inostroza PA, Lennquist A, Leslie HA, Maffini M, Slunge D, Trasande L, Warhurst AM, Muncke J (2019). Science of the total environment, 651, 3253-3268. 
Groh KJ, Muncke J (2017). In Vitro Toxicity Testing of Food Contact Materials: State-of-the-Art and Future Challenges. Comprehensive Reviews in Food Science and Food Safety.

doi.org/10.1111/1541-4337.12280

Gu F, Guo JG, Zhang W, Hall P (2017). From waste plastics to industrial raw materials: A life cycle assessment of mechanical plastic recycling practice based on a real-world case study. Science of The Total Environment 601-602, 1192-1207. DOI: 10.1016/j.scitotenv.2017.05.278

Hahladakis JN, Velis CA, Weber R, Iacovidou E, Purnell P (2018). An overview of chemical additives present in plastics: Migration, release, fate and environmental impact during their use, disposal and recycling. Journal of Hazardous Materials, 344, 179-199.

He Z, Li G, Chen J, Huang Y, An T, Zhang G (2015). Pollution characteristics and health risk assessment of volatile organic compounds emitted from different plastic solid waste recycling workshops. Environ. Int., 77, 85-94.

Hopewell J, Dvorak R, Kosinor E (2009). Plastics recycling: challenges and opportunities. Philos. Trans. R Soc. Lond. B Biol. Sci., 364, 2115-2126.

Huang DY, Zhou SG, Hong W, Feng WF, Tao L (2013). Pollution characteristics of volatile organic compounds, polycyclic aromatic hydrocarbons and phthalate esters emitted from plastic waste recycling granulation plants in Xingtan Town South China. Atmos. Environ., 71, 327-334.

Ignatyev IA, Thielemans W, van der Beke B (2014). Recycling of polymer: A review. ChemSusChem, 7, 1579-1593.

ILSI (2017). ILSI report Packaging materials. 1. Polyethylene terephthalate (pet) for food packaging applications. Updated Version.

Ionas AC, Dirtu AC, Anthonissen T, Neels H, Covaci A (2014). Downsides of the recycling process: harmful organic chemicals in children's toys. Environ. Int., 65, 54-62.

Jonker W, Zwart N, Stöckl JB, de Koning S, Schaap J, Lamoree MH, Somsen GW, Hamers T, Kool J (2017). Continuous fraction collection of gas chromatographic separations with parallel mass spectrometric detection applied to cell-based bioactivity analysis. Talanta, 168, 162-167.

Kanwal F, Waraich SM, Jamil T (2007). FT-IR analysis of recycled polystyrene for food packaging. J. Chem. Soc. Pakistan 29, 239-242.

Karayannidis G, Chatziavgoustis A, Achilias D (2002). Poly (ethylene terephthalate) recycling and recovery of pure terephthalic acid by alkaline hydrolysis. Adv. Polym. Technol., 21, 250-259.

Karayannidis GP, Achilias DS (2007). Chemical Recycling of Poly(ethylene terephthalate). Macromol. Mater. Eng., 292, 128-146.

Keresztes S, Tatar E, Czegeny Z, Zaray G, Mihucz VG (2013). Study on the leaching of phthalates from polyethylene terephthalate bottles into mineral water. Sci. Total Environ, 458, 451-458.

Koster S, Bani-Estivals MH, Bonuomo M, Bradley E, Chagnon MC, Garcia ML, Godts F, Gude T, Helling R, Paseiro-Losada P, Pieper G, Rennen M, Simat T, Spack L (2015). Guidance of Best Practices on the Risk Assessment of NIAS in Food Contact Materials and Articles, ILSI Europe Report Series. 2015, 1-70.

Koster S, Rennen M, Leeman W, Houben G, Muilwijk B, van Acker F, Krul L (2014). A novel safety assessment strategy for non-intentionally added substances (NIAS) in carton food contact materials, Food Additives \& Contaminants: Part A, 31, 422-443.

Kuang X, Shi Q, Zhou Y, Zhao Z, Wang T, Qi HJ (2018). Dissolution of epoxy thermosets via mild alcoholysis: The mechanism and kinetics study. RSC advances, 8, 1493-1502.

Labunska I, Harrad S, Santillo D, Johnston P, Brigden K (2013). Levels and distribution of polybrominated diphenyl ethers in soil sediment and dust samples collected from various electronic waste recycling sites within Guiyu town, southern China. Environ. Sci.: Processes impacts., 15, 503-511.

Lee J, Pedersen AB, Thomsen M (2014). The influence of resource strategies on childhood phthalate exposure - the role of REACH in a zero waste society. Environ. Int., 73, 312-322.

Leeman W, Krul L (2015). Non-intentionally added substances in food contact materials: How to ensure consumer safety, Current Opinion in Food Science, 6, 33-37.

Li-Carrillo C, Porter W, Ford OP, Nadella B (2016). Recycled Cotton for Gap Inc., MIT Sloane School of Management, Boston.

Lopez MDC, Pernas AIA, Lopez MJA, Latorre AL, Vilarino JML, Rodríguez MVG (2014). Assessing changes on poly(ethylene terephthalate) properties after recycling: mechanical recycling in laboratory versus postconsumer recycled material. Mater. Chem. Phys., 147, 884-894. 
Luongo G, Iadaresta F, Moccia E, Ostman C, Crescenzi C (2016). Determination of aniline and quinoline compounds in textiles. Journal of Chromatography $A, 1471,11-18$.

Luongo G, Thorsén G, Ostman C (2014). Quinolines in clothing textiles-A source of human exposure and wastewater pollution? Anal. Bioanal. Chem., 406, 2747-2756.

Maris J, Bourdon S, Brossard JM (2018). Mechanical recycling: Compatibilization of mixed thermoplastic wastes. Polymer degradation and stability, 147, 245-266.

Martínez-Bueno MJ, Gómez Ramos MJ, Bauer A, Fernández-Alba AR, (2019). An overview of nontargeted screening strategies based on high resolution accurate mass spectrometry for the identification of migrants coming from plastic food packaging materials. TrAC Trends in Analytical Chemistry 110, 191-203.

Martínez-Bueno MJ, Hernando MD, Uclés S, Rajski L, Cimmino S, Fernández-Alba AR, (2017). Identification of non-intentionally added substances in food packaging nano films by gas and liquid chromatography coupled to orbitrap mass spectrometry. Talanta 172, 68-77.

Muncke J, Backhaus T, Geueke B, Maffini MV, Martin OV, Peterson Myers J, Soto AM, Trasande L, Trier X, Scheringer M (2017). Scientific Challenges in the Risk Assessment of Food Contact Materials. Environmental Health Perspectives, 125, 095001. doi: 10.1289/EHP644.

Muthu SS, Li Y, Hu JY, Mok PY (2012). Recyclability Potential Index (RPI): The concept and quantification of RPI for textile fibres, Ecological Indicators, 18, 58-62.

NEA (2013). Hazardous substances in plastic materials (TA-3017/2013), Norwegian Environment Agency (NEA). Oslo, Norway.

Nerin C, Albinana J, Philo MR, Castle L, Raffael B, Simoneau C (2003). Evaluation of some screening methods for the analysis of contaminants in recycled polyethylene terephthalate flakes. Food Addit. Contam., 20, 668-677.

Peters RJB, Groeneveld I, Lopez Sanchez P, Gebbink W, Gerssen A, de Nijs M, van Leeuwen SPJ (2019). Review of analytical approaches for the identification of non-intentionally added substances in paper and board food contact materials. Trends in Food Science and Technology, 85, 44-54.

Peterson A (2014). Anna Peterson, PhD Thesis: Towards Recycling of Textile Fibres: Separation and Characterization of Textile Fibers and Blends. Master's Thesis: Chalmers University of Technology.

Pickering SJ, Kelly RM, Kennerley JR, Fenwick NJ (2000). A fluidised-bed process for the recovery of glass fibres from scrap thermoset composites. Composites sciences and technology, 60:509-523.

Pieke EN, Granby K, Teste B, Smedsgaard J, Riviére G (2018a). Prioritization before risk assessment: The viability of uncertain data on food contact materials. Regulatory Toxicology and Pharmacology, 97, 134-143. doi: 10.1016/j.yrtph.2018.06.012.

Pieke EN, Granby K, Trier X, Smedsgaard J (2017). A framework to estimate concentration of potentially unknown substances by semi-quantification in liquid chromatography electrospray ionization mass spectrometry. Analytica Chimica Acta, 975, 30-41.

Pieke EN, Smedsgaard J, Granby K (2018b). Exploring the chemistry of complex samples by tentative identification and semi-quantification: a food contact material case. J. Mass Spectrom., 53, 323335. doi.org/10.1002/jms.4052.

Pivnenko K, Eriksen MK, Martín-Fernández JA, Eriksson E, Astrup TF (2016). Recycling of plastic waste: Presence of phthalates in plastics from households and industry, Waste Management, 54, 44-52.

Pivnenko K, Granby K, Eriksson E, Astrup TF (2017). Recycling of plastic waste: Screening for brominated flame retardants, Waste Manag., 69, 101-109. doi: 10.1016/j.wasman.2017.08.038.

Plastics Europe (2016). Plastics - the facts 2016. http://www.plasticseurope.org/documents/document/20161014113313plastics_the_facts_2016_final_version.pdf

Puype F, Samsonek J, Knoop J, Egelkraut-Holtus M, Ortlieb M (2015). Evidence of waste electrical and electronic equipment (WEEE) relevant substances in polymeric food-contact articles sold on the European market. Food Additives \& Contaminants: Part A Chem. Anal. Control Exposure Risk Assess., 32, 410-426.

Puype F, Samsonek J, Vilimkova V, Kopeckova S, Ratiborska A, Knoop J (2017). Towards a generic procedure for the detection of relevant contaminants from waste electric and electronic equipment (WEEE) in plastic food-contact materials: a review and selection of key parameters. Journal Food Additives \& Contaminants: Part A. 34, 1767-1783.

Safer Made (2018). Safer Chemistry Innovation in the Textile and Apparel Industry, Fashion for Good. 
Samsonek J, Puype F (2013). Occurrence of brominated flame retardants in black thermo cups and selected kitchen utensils purchased on the European market. Food Addit. Contam.: Part A. 30, 1976-1986.

Schymanski EL, Jeon J, Gulde R, Fenner K, Ruff M, Singer HP, Hollender J (2014). Identifying Small Molecules via High Resolution Mass Spectrometry: Communicating Confidence. Environmental Science \& Technology, 48, 2097-2098.

Shawaphun S, Manangan T, Wacharawichanant S (2010). Thermo- and photo-degradation of LDPE and PP films using metal oxides as catalysts. Trans Tech Publications Ltd., 93, 505-508.

Shuaib NA, Mativenga PT (2017). Carbon footprint analysis of fibre reinforced composite recycling processes. Procedia manufacturing, 7, 183-190.

Sokoli HU, Simonsen ME, Sogaard EG (2017). Investigation of degradation products produced by recycling the solvent during chemical degradation of fiber-reinforced composites. Journal of reinforced plastcs and composites, 36, 1286-1296.

Song XC, Wrona M, Nerin C, Lin QB, Zhong HN (2019). Volatile non-intentionally added substances (NIAS) identified in recycled expanded polystyrene containers and their migration into food simulants. Food Packaging and Shelf Life 20, 100318.

Soroudi A, Jakubowicz I (2013). Recycling of bioplastics, their blends and biocomposites: A review. European Polymer Journal, 49, 2839-2858.

Stenmarck A, Belleza EL, Fråne A, Busch N, Larsen A, Wahlström M (2017). Hazardous substances in plastics: ways to increase recycling. Report number C 233, ISBN 978-91-88319-51-7. IVL Swedish Environmental Research Institute.

Tang Z, Huang Q, Cheng J, Yang Y, Guo W, Nie Z, Zeng N, Jin L (2014). Polybrominated diphenyl ethers in soils, sediments, and human hair in a plastic waste recycling area: a neglected heavily polluted area. Environ. Sci. Technol., 48, 1508-1516.

Tang Z, Huang Q, Yang Y, Nie Z, Cheng J, Yang J, Wang Y, Chai M (2016). Polybrominated diphenyl ethers (PBDEs) and heavy metals in road dusts from a plastic waste recycling area in North China: implications for human health. Environ. Sci. Pollut. Res., 23, 625-627.

Tang Z, Zhang L, Huang Q, Yang Y, Nie Z, Cheng J, Yang J, Wang Y, Chai M (2015). Contamination and risk of heavy metals in soils and sediments from a typical plastic waste recycling area in North China. Ecotoxicol. Environ. Saf., 122, 343-351.

Tue NM, Goto A, Takahashi S, Itai T, Asante KA, Kunisue T, Tanabe S (2016). Release of chlorinated, brominated and mixed halogenated dioxin-related compounds to soils from open burning of ewaste in Agbogbloshie (Accra Ghana). J. Hazard. Mater., 302, 151-157.

Van Bossuyt M, Van Hoeck E, Raitano G, Manganelli S, Braeken E, Ates G, Vanhaecke T, Van Miert S, Benfenati E, Mertens B, Rogiers V (2017). (Q)SAR tools for priority setting: a case study with printed paper and board food contact material substances. Food Chem. Toxicol., 102, 109-119.

van Leeuwen SPJ, Bovee TFH, Awchi M, Klijnstra MD, Hamers ARM, Hoogenboom RLAP, Portier L, Gerssen A (2019) BPA, BADGE and analogues: A new multi-analyte LC-ESI-MS/MS method for their determination and their in vitro (anti)estrogenic and (anti)androgenic properties. Chemosphere, 221, 246-253.

Vera P, Canellas E, Barknowitz G, Goshawk J, Nerin C (2019). Ion-mobility QTOF mass spectrometry: a novel technique applied to migration of non-intentionally added substances (NIAS) from polyethylene films intended for use as food packaging. Anal. Chem., 91, 12741-12751.

Veyrand J, Marin-Kuan M, Bezencon C, Frank N, Guérin V, Koster S, Latado H, Mollergues J, Patin A, Piguet D, Serrant P, Varela J, Schilter B (2017). Integrating bioassays and analytical chemistry as an improved approach to support safety assessment of food contact materials, Food Additives \& Contaminants: Part A, 34, 1807-1816.

Vilaplana F, Ribes-Greus A, Karlsson S (2007). Analytical strategies for the quality assessment of recycled high-impact polystyrene: A combination of thermal analysis, vibrational spectroscopy, and chromatography. Analytica Chimica Acta ${ }_{\llcorner} 604,18-28$.

Wang Y (2010). Fiber and Textile Waste Utilization, Waste Biomass Valor. 1, 135-143.

Yamashita K, Yamamoto N, Mizukoshi A, Noguchi M, Ni Y, Yanagisawa Y (2009). Compositions of Volatile Organic Compounds Emitted from Melted Virgin and Waste Plastic Pellets. Journal of the Air \& Waste Management Association, 59, 273-278.

Yang Y, Boom R, Irion B, van Heerden DJ, Kuiper P, de Wit H (2012). Recycling of composite materials. Chemical engineering and processing: Process intensification, 51, 53-68. 
Yang Y, Lu Y, Xiang H, Xu Y, Li Y (2002). Study on methanolytic depolymerization of PET with supercritical methanol for chemical recycling. Polym. Degrad. Stab., 75, 185-191.

Zwart N, Nio SH, Houtman CJ, de Boer J, Kool J, Hamers T, Lamoree MH (2018) High-Throughput Effect-Directed Analysis Using Downscaled in Vitro Reporter Gene Assays To Identify Endocrine Disruptors in Surface Water. Environ. Sci. Technol. 52, 4367-4377 


\section{Annex 1 An overview of 238 hazardous substances likely associated with plastic packaging}

\begin{tabular}{|c|c|c|c|}
\hline Substance & CAS & Function & Plastic type \\
\hline \multicolumn{4}{|l|}{ Antimicrobial substances } \\
\hline 3-iodo-2-propynyl-N-butyl carbamate & 55406-53-6 & antimicrobial & \\
\hline arsenic and its compounds & \multicolumn{2}{|c|}{ 7440-38-2, 7778-39-4, 58-36-6, 1:antimicrobial } & Plastisiced PVC, PUR, LDPE, PESs \\
\hline bis(tributyltin)oxide (TBTO) & $56-35-9$ & antimicrobial & PUR foam, other polymers (unspecified) \\
\hline dichlorophen & $97-23-4$ & antimicrobial & \\
\hline ethyl 4-hydroxybenzoate & $120-47-8$ & antimicrobial & \\
\hline fentin acetate & $900-95-8$ & antimicrobial & \\
\hline fentin hydroxide & 76-87-9 & antimicrobial & \\
\hline methyl 4-hydroxybenzoate & $99-76-3$ & antimicrobial & \\
\hline naphthenic acids, copper salts & $1338-02-9$ & antimicrobial & \\
\hline organic tin compounds (tributyltin, triphenyltin, dibutyltin, dioctyltin) & \multicolumn{2}{|c|}{ 76-63-1, 76-87-9, 379-52-2, 639-5 antimicrobial } & PUR foam, PVC, paint \\
\hline propyl 4-hydroxybenzoate & $94-13-3$ & antimicrobial & \\
\hline silver sodium hydrogen zirconium phosphate & $155925-27-2$ & antimicrobial & \\
\hline thiram (tetramethylthiuram disulfide) & $137-26-8$ & antimicrobial & \\
\hline triclosan & $3380-34-5$ & antimicrobial & $P E, P P, P V C, P E S$ fibres, PA fibres \\
\hline ziram (zinc bis(dimethyldithiocarbamate)) & $137-30-4$ & antimicrobial & \\
\hline \multicolumn{4}{|l|}{ Blowing agents } \\
\hline butane & $106-97-8$ & blowing agents & \\
\hline$C, C^{\prime}$-azodi(formamide) (ADCA) & $123-77-3,97707-96-5$ & blowing agents & PVC, PE, epoxy resins \\
\hline chloromethane, methyl chloride & $74-87-3$ & blowing agents & PS, PE, PP, PUR, phenol resins, acetylcellulose foam \\
\hline fluorinated greenhouse gasses (HFCs, PFCs and SF6) & \multicolumn{2}{|c|}{ 811-97-2, 354-33-6, 420-46-2, 75-blowing agents } & PUR foam, PS foam, phenolic foam \\
\hline isobutane & $75-28-5$ & blowing agents & \\
\hline
\end{tabular}




\begin{tabular}{|c|c|c|c|}
\hline \\
\hline \multicolumn{4}{|l|}{ 4,4-methylenedianiline } \\
\hline 4-methyl-m-phenylenediamine & $95-80-7$ & colorant & \\
\hline 5-methyl-2-phenyl- $1 \mathrm{H}$-indole & $13228-36-9$ & colorant & \\
\hline cadmium and its compounds & \multicolumn{2}{|c|}{ 7440-43-9, 10108-64-2, 542-83-6, pigment } & PVC (stabiliser), all plastics (pigment) \\
\hline chromium and its compounds & \multicolumn{2}{|c|}{ 1333-82-0, 7778-50-9, 7789-09-5, pigment } & PVC, PE, PP etc \\
\hline chromium trioxide & $1333-82-0$ & colorant & PE etc \\
\hline cobalt(II) diacetate & 71-48-7 & pigment & PET \\
\hline disodium 3,3-[(1,1-biphenyl]-4,4-diylbis(azo)bis(4-aminonaphthalene- & $573-58-0$ & colorant & \\
\hline disodium 4 amino-3-[(4-[(2,4-diaminophenyl)azo $][1,1$-biphenyl]-4-yl] a: & $1937-37-7$ & colorant & \\
\hline disperse Yellow 32 & $2832-40-8$ & colorant & Yellow coloured plastics \\
\hline lead and its compounds & $75-74-1,78-00-2,301-04-2,1072$ & -pigment & PVC (stabiliser), all plastics (pigment) \\
\hline lead chromate & $7758-97-6$ & pigment & All plastics \\
\hline lead chromate molybdate sulphate red (C.I. Pigment Red 104) & $12656-85-8$ & pigment & All plastics \\
\hline lead sulfochromate yellow (C.I. Pigment Yellow 34) & $1344-37-2$ & pigment & HDPE, LDPE, PVC, CA, PP \\
\hline malachite green hydrochloride, malachite green oxalate & $569-64-2,18015-76-4$ & colorant & Green coloured plastics. \\
\hline solvent Yellow 143 & 842-07-9 & colorant & Yellow coloured plastics \\
\hline
\end{tabular}




\section{Flame retardants}

1,2,5,6- tetrabromocyclooctane (TBCO)

2,4,6-tribromophenyl allyl ether

2-ethylhexyl diphenyl phosphate

$6 \mathrm{H}$-dibenz[c,e][1,2]oxaphosphorin, 6-oxide (DOPO)

aluminium diethylphosphinate

aluminium hydroxide

ammonium polyphosphate ( $\left.\mathrm{NH}_{4} \mathrm{PO} 3\right) \mathrm{n}$

antimony trioxide

BFRS PBDEs (PeBDE, OBDE, DBDE, HBCDD, TBBPA)

bis(3-chloro-1-propyl) (1-chloro-2-propyl) phosphate

bis(hexachlorocyclopentadie no) cyclooctane

bisphenol A bis-(diphenyl phosphate) (BAPP)

boric acid

decabromodiphenyl e thane (DBDPE)

diphe nyl cresyl phosphate

e thylene (bistetrabromophthalimide) (EBTEBP

hexabromocyclododecane (HBCDD) and all major diaste reoisomers

magnesium hydroxide

melamine cyanurate

melamine polyphosphate

molybdenum trioxide

$\mathrm{N}$-alkoxy hindered amine reaction products

organo phosphates (TCPP, TDCPP, TPP)

phosphonate oligomer, polyphosphonate

phosphoric add, diethyl-, aluminium salt

poly-(m-phenylene methylphosphonate)(Fyrol PMP)

poly(phosphonate-cocarbonate)

red phosphorus

resorcinol bis-diphenylphosphate

sodium borate, decahydrate

sodium tetraborate, anhydrous

sodium tetraborate, pentahydrate

TDCP (tris[2-chloro-1-(chloromethyl)ethyl] phosphate) 13674-87-8

tetrabromobisphenol A bis (2,3-dibromopropyl) ether (TBBPA-DBPE) 21850-44-2

tetrabromobisphenol A bis (allyl ether)

tetrachlorophtalic anhydride

tetrakis(2,6-dimethylphenyl)-m-phenylene biphosphate

triphenyl phosphate

triphenyl phosphate (TPP)

tris(2-chloro-1-methylethyl) phosphate

tris(2-chloroethyl) phosphate

tris(tribromoneopentyl) phosphate (TRBNPP

tris(tribromophenoxy) triazine (TTBPTAZ)

trixylyl phosphate

zinc borate
3194- 57-8

$3278-89-5$

$241-94-7$

35948-25-5

21645-51-2

68333-79-9

1309-64-4

32534-81-9, 32536-52-0, 1163-19 flame retardant

137888-35-8

$13560-89-9$

10043-35-3

84852-53-9

(2) $444-49-5$

$1309-42-8$

37640-57-6

15541-60-3

191680-81-6

63747-58-0

$226-90-5$

$7723-14-0$

125997-21-9

1303-96-4

$21850-44-2$

$117-08-8$

139189-30-3

115-86-6

115-86-6

13674-84-5

115-96-8

19186-97-1

25713-60-4

25155-23-1

1332-07-06, 138265-88-0 flame retardant

tardant

mame retardant

flame retardant

flame retardant

flame retardant

flame retardant

flame retardant

flame retardant

flame retardant

flame retardant

flame retardan

ame retardant

e retardant

lame retardant

flame retardant

flame retardant

flame retardant

flame retardant

flame retardant

flame retardant

flame retardant

flame retardant

flame retardant

flame retardant

flame retardant

flame retardant

flame retardant

flame retardant

flame retardant

flame retardant

flame retardant

flame retardant

flame retardant

flame retardant

flame retardant

flame retardant

flame retardant
EPS

Epoxy, PA, PBT, PET, TPU

EVA, PE, thermosets

PE, PP

Various plastics

ABS, EPS, HIPS, PAs, PBT, PE, PP, e poxy, PES, PUR, PU

CPE, engineering the rmoplastics, HIPS, PE, PP, therm PPE (high impact) and HIPS

PS, PVC, synthetic rubber

CPE, Engine ering thermoplastics, HIPS, PE, PP, therm HIPS (flame retardant), PVC (plasticiser)

HIPS, PP, PP, PBT, OPET, PC, engineering thermoplast EPS, XPS, HIPS, polymer dispersions on textiles EVA, PA, PE, PP

Polyacrylate, PBT, TPU, UP

Epoxy resins, phe nolic based composites, polyacryla PES, PVC

PE, PP

PUR (foam)

Thermosets

Epoxies

Epoxies

Engineering plastics (and e lastome rs)

Epoxy resins, polyacrylate, polyacrylate 66, PP

PPE-HIPS, PC-ABS

ABS, HIPS, Phenolic resins, epoxy-laminate

EPS

Styrene based plastics

PPE-HIPS, PC-ABS, CA

PP

ABS, HIPS

PUR, PVC, EVA, PE, PP 


\begin{tabular}{|c|c|c|c|}
\hline \multicolumn{4}{|l|}{ Monomer or intermediate } \\
\hline (epoxyethyl)benzene & $96-09-3$ & monomer or intermediate & \\
\hline 1,1-dichloroethylene & $75-35-4$ & monomer & Saran \\
\hline 1,2,3-trichloropropane & $96-18-4$ & monomer or intermediate & \\
\hline 1,2-epoxy-4-epoxyethylcyclohexane & $106-87-6$ & monomer & Epoxies \\
\hline 1,2-epoxybutane & $106-88-7$ & intermediate & Epoxies \\
\hline 1,3-bis(2,3-epoxypropoxy)benzene & $101-90-6$ & monomer or intermediate & Epoxies \\
\hline 1,3-butadiene & $106-99-0$ & monomer & HIPS \\
\hline 1,4-diaminobutane (Putrescine) & $110-60-1$ & intermediate & Nylon- 4,6 \\
\hline 1,4-dichlorobenzene & $106-46-7$ & monomer & PPS \\
\hline 1,5-naphthylenediamine & $2243-62-1$ & intermediate & PUR \\
\hline 2-((2-aminoethyl)amino)ethanol & $111-14-1$ & monomer or intermediate & \\
\hline 2-chlorobuta-1,3-diene & $126-99-8$ & monomer or intermediate & \\
\hline 4-(1,1,3,3-tetramethylbutyl)phenol, (4-tert-Octylphenol) & $140-66-9$ & monomer or intermediate & Phenol resins \\
\hline 4,4'- diaminodiphenylmethane (MDA) & $101-77-9$ & intermediate & Epoxy coatings and composites, and the high-perforr \\
\hline 4-tert-butylphenol, 2,6-di-tert-butylphenol & $98-54-4,128-39-2$ & intermediate & Phenolic resins, PC \\
\hline acrylamide & 79-06-01 & intermediate & Polyacrylamide, polyacrylonitrile copolymer \\
\hline acrylonitrile & $107-13-1$ & monomer & ABS, SAN, ASA \\
\hline allyl 2,3-epoxypropyl ether & $106-92-3$ & intermediate & Epoxies \\
\hline aziridine & $151-56-4$ & monomer or intermediate & \\
\hline biphenyl & $92-52-4$ & monomer or intermediate & \\
\hline bisphenol A (BPA) & $80-05-07$ & monomer & $\mathrm{PC}$, epoxy resins, phenoplast cast resin, $\mathrm{PVC}$, rigid $\mathrm{PL}$ \\
\hline bisphenol F (BPF) & $620-92-8$ & monomer or intermediate & \\
\hline bisphenol S (BPS) & $80-09-1$ & monomer or intermediate & \\
\hline butyl 2,3-epoxypropyl ether & $6-8-2426$ & intermediate & Epoxies \\
\hline chloroethylene & $75-01-4$ & monomer or intermediate & \\
\hline epichlorohydrin & $106-89-8$ & monomer or intermediate & \\
\hline formaldehyde & $50-00-0$ & monomer & Melamine, phenolic resins, acetal resins, POM \\
\hline formaldehyde, oligomeric reaction products with aniline & $25214-70-4$ & intermediate & Epoxy resins, high performance polymers \\
\hline glycidyl methacrylate & $106-91-2$ & monomer or intermediate & \\
\hline hexahydro-2-benzofuran-1,3-dione and similar compounds & $85-42-7,13149-00-3,14166-21-3$ & intermediate & Epoxy resins \\
\hline hexahydromethylphthalic anhydride and similar compounds & $25550-51-0,19438-60-9,48122-1$ & 1. intermediate & PESs, plasticisers manufactured from the substance, \\
\hline hydrazine & $302-01-2,7803-57-8$ & intermediate & PUR \\
\hline imidazole & $288-32-4$ & intermediate & PU and epoxy \\
\hline isooctyl acrylate & $29590-42-9$ & monomer or intermediate & \\
\hline methylene diphenyl diisocyanate (MDI), toluene-diisocyanate, TDI & $26447-40-5,5873-54-1,101-68-8$ & 3, intermediate & PUR \\
\hline methyloxirane (propylene oxide) & $75-56-9$ & monomer or intermediate & PUR, thermoplastics \\
\hline m-phenylenediamine & $108-45-2$ & monomer or intermediate & \\
\hline naphthalene & $91-20-3$ & monomer or intermediate & \\
\hline phenol & $108-95-2$ & monomer & Bakelite (phenol-formaldehyde) \\
\hline styrene & $100-42-5$ & intermediate & PS, ABS, SAN, EPS, glassfiber reinforced products (st \\
\hline trizinc bis(orthophosphate) & $7779-90-0$ & monomer or intermediate & \\
\hline vinyl acetate & $108-05-4$ & monomer & PVA, VA/AA, PVCA \\
\hline zinc & $7440-66-6$ & monomer or intermediate & \\
\hline zinc chloride & 7646-85-7 & monomer or intermediate & \\
\hline zinc sulphate & $7733-02-0$ & monomer or intermediate & \\
\hline
\end{tabular}




\begin{tabular}{|c|c|c|c|}
\hline \multicolumn{4}{|l|}{ Stabilisers } \\
\hline 1,3,5-tris(oxiranylmethyl)-1,3,5-triazine-2,4,6(1H,3H,5H)-trione & $2451-62-9$ & stabilizer & \\
\hline 1,4-benzenediol, 2,5-bis(1,1-dimethylethyl)- & $88-58-4$ & stabilizer & \\
\hline 2-(2H-benzotriazol-2-yl)-4-(tert-butyl)-6-(sec-butyl)phenol & $36437-37-3$ & stabilizer & Formaldehyde resins \\
\hline 2-(2'-hydroxy-3,5'-di-t-amylphenyl)benzotriazole & $25973-55-1$ & stabilizer & Formaldehyde resins \\
\hline 2-(5-chloro-2H-benzotriazol-2-yl)-4,6-bis(1,1-dimethylethyl)-phenol & $3864-99-1$ & stabilizer & Formaldehyde resins \\
\hline 2,2',4,4'-tetrahydroxybenzophenone & $131-55-5$ & stabilizer & \\
\hline 2,4-dihydroxybenzophenone & $131-56-6$ & stabilizer & \\
\hline 2,4-di-tert-butylphenol & 96076-4 & stabilizer & \\
\hline 2-benzotriazol-2-yl-4,6-di-tert-butylphenol & $3846-71-7$ & stabilizer & Formaldehyde resins \\
\hline 2-ethylhexanoic acid & $149-57-5$ & stabilizer & PVC and as residue in PUR products \\
\hline 2-ethylhexyl 10-ethyl-4,4-dioctyl-7-oxo-8-oxa-3,5-dithia-4-stannatetra & ( 15571-58-1 & stabilizer & \\
\hline 2-hydroxy-4-methoxybenzophenone & $131-57-7$ & stabilizer & \\
\hline 2-tert-butyl-6-(5-chloro-2H-benzotriazol-2-yl)-4-methylphenol & $3896-11-5$ & stabilizer & Formaldehyde resins \\
\hline butylated hydroxyanisole (BHA) & $25013-16-5$ & stabilizer & \\
\hline butylated hydroxytoluene (BHT) & $128-37-0$ & stabilizer & \\
\hline dibutyltin dichloride & $683-18-1$ & stabilizer & PVC, PUR \\
\hline dibutyltin dilaurate & 77-58-7 & stabilizer & \\
\hline diphenylamine & $122-39-4$ & stabilizer & \\
\hline DMT EHMA, DMTC etc. 4 & 57583-35-4, 15571-58-1, 77-58-7 & stabilizer & \\
\hline $\mathrm{N}$-2-naphthylaniline, $\mathrm{N}$-phenyl-2-naphthylamine & $135-88-6$ & stabilizer & $P E, E V A, P I B$ \\
\hline triphenyl phosphite & $101-02-0$ & stabilizer & \\
\hline tris(nonylphenyl)phosphite, TNPP & $26523-78-4$ & stabilizer & PVC, LLDPE, HDPE \\
\hline zinc oxide & $1314-13-2$ & stabilizer & \\
\hline
\end{tabular}




\section{Plasticisers}

1,2-benzenedicarboxylic acid, di-C6-8-branched alkyl esters, C7-rich (Di 71888-89-6

1,2-benzenedicarboxylic acid, di-C7-11-branched and linear alkyl esters 68515-42-4

1,4-benzenedicarboxylic acid, bis(2-ethylhexyl) ester

6422-86-2

$2,2^{\prime}, 6,6^{\prime}$-tetrabromobisphenol A

$79-94-7$

acetyl tributyl citrate (ATBC)

alkanes, C10-13, chloro (Short Chain Chlorinated Paraffins-SCCP)

benzyl butyl phthalate (BBP)

bis (2-ethylhexyl)phthalate (DEHP)

$77-90-7$

bis(2-methoxyethyl) phthalate (DMEP)

di-allyl phthalate

dibutyl phthalate (DBP)

85-68-7

$117-81-7$

$117-82-8$

$6422-86-2$

dicyclohexyl phthalate (DCHP)

di-ethyl phthalte

dihexyl phthalate

diisobutyl phthalate (DiBP)

di-isodecyl phthalate

di-isoheptyl phthalate

diisononyl adipate (DINA)

diisononyl-cyclohexane-1,2-carboxylate (DINCH) -

di-isooctyl phthalate

dimethoxyethyl phthalate

DINP, DIDP, DPHP, DEP, DIPP, DHP5

di-octyl phthalate

dipropylene glycol dibenzoate (DGD)

di-undecyl phthalate

glycerol triacetate (GTA)

medium-chain chlorinated paraffins, $\mathrm{C} 14-17$

$131-17-9$

84-74-2

$84-61-7$

84-66-2

$84-75-3$

84-69-5

26761-40-0

71888-89-6

33703-08-1

$166412-78-8$

$27554-26-3$

$117-82-8$

\begin{tabular}{|c|c|}
\hline plasticiser & PVC, one-component PURs and acrylics \\
\hline plasticiser & PVC (mainly), foamed urethane \\
\hline \multicolumn{2}{|l|}{ plasticiser } \\
\hline \multicolumn{2}{|l|}{ plasticiser } \\
\hline plasticiser & PVC etc \\
\hline 7. plasticiser & PVC, rubber, elastomers, textile fiber cover \\
\hline plasticiser & PVC, PMMA, PA, thermoplastic PES \\
\hline plasticiser & PVC, PMMA, ABS, PA, PS, thermoplastic PES \\
\hline plasticiser & Nitrocellulose, acetyl cellulose, PVA, PVC and PVDC \\
\hline plasticiser & PVC etc \\
\hline \multicolumn{2}{|l|}{ plasticiser } \\
\hline plasticiser & PVC, PP, PVA-based adhesives, plasticiser-solvent \\
\hline \multicolumn{2}{|l|}{ plasticiser } \\
\hline \multicolumn{2}{|l|}{ plasticiser } \\
\hline \multicolumn{2}{|l|}{ plasticiser } \\
\hline plasticiser & PVC, PS, nitrocellulose, celluloseether, polyacrylate \\
\hline \multicolumn{2}{|l|}{ plasticiser } \\
\hline \multicolumn{2}{|l|}{ plasticiser } \\
\hline plasticiser & PVC etc \\
\hline plasticiser & PVC etc \\
\hline \multicolumn{2}{|l|}{ plasticiser } \\
\hline \multicolumn{2}{|l|}{ plasticiser } \\
\hline 4! plasticiser & PVC and other plastic materials including PVA, cellu \\
\hline \multicolumn{2}{|l|}{ plasticiser } \\
\hline plasticiser & PVC etc \\
\hline \multicolumn{2}{|l|}{ plasticiser } \\
\hline plasticiser & PVC etc \\
\hline plasticiser & Soft plastic, PVC, and PES \\
\hline \multicolumn{2}{|l|}{ plasticiser } \\
\hline plasticiser & PVC etc \\
\hline plasticiser & Cellulose based plastics etc \\
\hline astic & PVCetc \\
\hline
\end{tabular}

sulfonic acids, C10-C18-alkane, phenylesters (ASE)

tributyl phosphate

trimethyl pentaryl diisobutyrate (TXIB)

$68515-48-1$

27138-31-4

$3648-40-0$

102-76-1

$85535-85-9$

85535-84-8

91082-17-

126-73-8

6846-50-0

plasticiser

PVC etc 


\begin{tabular}{|c|c|c|c|}
\hline \multicolumn{4}{|l|}{ Solvents } \\
\hline (R)-p-mentha-1,8-diene & $5989-27-5$ & solvent & \\
\hline 1,1,2-trichloroethane & $79-00-5$ & solvent & Teflon \\
\hline 1,2,3-trichloropropane & $96-18-4$ & solvent & Hexafluoropropylene \\
\hline 1,2,4-trimethylbenzene & $95-63-6$ & solvent & other hydrocarbon \\
\hline 1,4-dioxane & $123-91-1$ & solvent & Cellulose based polymers \\
\hline 1,6-hexanediol diglycidyl ether & 16096-31-4 & solvent & Epoxies, chlorinated vinyl resins \\
\hline 2-methoxyethanol & $109-86-4$ & solvent & Epoxy resins and polyvinylacetate \\
\hline benzene & $71-43-2$ & solvent & \\
\hline cyclohexane & $110-82-7$ & solvent & \\
\hline dichloromethane & $75-09-02$ & solvent & PC \\
\hline dimethylformamide & $68-12-2$ & solvent & Polyacrylonitrile, PUR and polyvinylchloride \\
\hline dipentene & $138-86-3$ & solvent & \\
\hline distillates (petroleum), hydrotreated heavy naphthenic & $64742-52-5$ & solvent & \\
\hline distillates (petroleum), hydrotreated heavy paraffinic & 64742-54-7 & solvent & \\
\hline distillates (petroleum), hydrotreated middle & $64742-46-7$ & solvent & \\
\hline heptane & $142-82-5$ & solvent & \\
\hline naphtha & 8030-30-6 & solvent & \\
\hline naphtha (petroleum), heavy alkylate & $64741-65-7$ & solvent & \\
\hline naphtha (petroleum), hydrotreated light & $64742-49-0$ & solvent & \\
\hline naphtha (petroleum), light alkylate & $64741-66-8$ & solvent & \\
\hline petrolatum & $8009-03-8$ & solvent & \\
\hline solvent naphtha (petroleum), light aromatic & $64742-95-6$ & solvent & \\
\hline stoddard solvent & $8052-41-3$ & solvent & \\
\hline trichloroethylene & $79-01-6$ & solvent & PVC \\
\hline \multicolumn{4}{|l|}{ Accelerator } \\
\hline zinc bis(diethyldithiocarbamate) & $14324-55-1$ & accelerator & \\
\hline zinc bis(dibutyldithiocarbamate) & $136-23-2$ & accelerator & \\
\hline disulfiram (tetraethylthiuram disulfide) & $97-77-8$ & accelerator & \\
\hline di(benzothiazol-2-yl) disulphide & $120-78-5$ & accelerator & \\
\hline 2-mercaptobenzothiazole & $149-30-4$ & accelerator & \\
\hline
\end{tabular}




\section{Surfactant}

(Z)-9-octadecenamide

301-02-0

(Z)-octadec-9-enylamine

$112-90-3$

2-[2-[2-[2-(4-nonylphenoxy)ethoxy]ethoxy]ethoxy]ethanol

7311-27-5

4-nonylphenol, branched, ethoxylated

127087-87-0

4-tert-octylphenol

140-66-9

ammonium pentadecafluorooctanoate

dimethyldioctadecylammonium chloride

3825-26-1

isononylphenol ethoxylate

107-64-2

$37205-87-1$

$\mathrm{N}$-dodecyl-2-pyrrolidone

nonoxynol-1

nonylphenol

nonylphenol, branched, ethoxylated

2687-96-9

26027-38-3

25154-52-3

9016-45-9

surfactant or its degradation product

surfactant or its degradation product

surfactant or its degradation product

surfactant or its degradation pre

surfactant or its degradation product

surfactant or its degradation product

surfactant or its degradation product

surfactant or its degradation product

surfactant or its degradation product

surfactant or its degradation product

surfactant or its degradation product

surfactant or its degradation product

perfluorinated alkylated substances (PFAS); PFOS, PFOA and similar col 15166-06-0, 2395-00-8, 24216-05 surfactant or its degradatic PTFE, FEP, PVDF

perfluorooctanoic acid

phenol, 4-nonyl-, branched

$335-67-1$

surfactant or its degradation product

p-nonylphenol

$84852-15-3$

surfactant or its degradation product

104-40-5

surfactant or its degradation product 


\section{Annex 2 An overview of 43 classes of hazardous substances used in the textile sector}

\begin{tabular}{|c|c|c|}
\hline Substance & Function & Application \\
\hline \multicolumn{3}{|l|}{ Amines } \\
\hline Amines & $\begin{array}{l}\text { Auxiliaries including surfactants, dispersants and softeners, } \\
\text { or as process chemicals or precursors for other materials }\end{array}$ & Various manufacturing processes \\
\hline Aryl amines & $\begin{array}{l}\text { In polyurethanes and as decomposition products of azo } \\
\text { colorants }\end{array}$ & Mills \\
\hline $\begin{array}{l}\text { Quaternairy ammonium compounds (DTDMAC, DSDMAC, } \\
\text { DHTDMAC) }\end{array}$ & Disinfectants, cleaners, antimicrobial treatments & Finishing \\
\hline \multicolumn{3}{|l|}{ Dyes and residuals } \\
\hline Azo-dyes (arylamine releasers) & Dyes & Dye houses \\
\hline Hypochlorite & Bleaching & Dye houses, denim finishing \\
\hline Naphthalene & $\begin{array}{l}\text { Common residual found in synthetic leather tannins, and in } \\
\text { dye dispersing agents that use naphthalene sulfonate } \\
\text { derivatives }\end{array}$ & Leather production, dye houses \\
\hline Polyaromatic hydrocarbons (PAH) & $\begin{array}{l}\text { Residual in carbon black, dyes, rubber and other } \\
\text { petrochemical products }\end{array}$ & Dye houses \\
\hline $\begin{array}{l}\text { Sensitizing disperse dyes (ZDHC for subset of known } \\
\text { sensitizers, or GHS codes H317, H334, R43, R42) }\end{array}$ & $\begin{array}{l}\text { Dyes for synthetic fibres including polyester, acetate and } \\
\text { polyamide }\end{array}$ & Dye houses \\
\hline Titanium dioxide & Pigments & Dye houses \\
\hline \multicolumn{3}{|l|}{ Halogenated chemicals } \\
\hline Chlorinated and non-chlorinated MIT, CMIT & Antimicrobial and preservative for formulated products & Chemical manufacturers \\
\hline Chlorinated benzenes & Solvents and fibre swelling agents in dying process & Dye houses \\
\hline Chlorophenols & Hide preservation & Leather processing \\
\hline Halogenated flame retardants & Flame retardants & Fabric finishing \\
\hline Per- and poly-fluorinated compounds & Durable water repellency and stain repellency & Fabric finishing \\
\hline Short chain chlorinated paraffin & Leather conditioners & Leather production \\
\hline Triclosan and triclocarban & Antimicrobial fabric treatment & Fabric finishing \\
\hline
\end{tabular}




\begin{tabular}{|c|c|c|}
\hline \multicolumn{3}{|l|}{ Metals } \\
\hline Arsenic & $\begin{array}{l}\text { Some pesticides/defoliants for cotton; can be a contaminant } \\
\text { in other materials and dyes }\end{array}$ & Cotton farms \\
\hline Cadmium & Some pigments and coating & $\begin{array}{l}\text { Many parts of the supply chain based on } \\
\text { function }\end{array}$ \\
\hline Cadmium (PVC stabilizer) & Stabilizer in PVC & \\
\hline Antimony (catalysts) & PET catalyst & Various manufacturing processes \\
\hline Chromium (leather) & Tanning agent & Mills \\
\hline Chromium (wool) & Mordant for mordant dyes used for dark shades of wool & Dye houses \\
\hline Lead & Plastics, paints, unks, pigments, surface coatings & Mills \\
\hline Mercury & $\begin{array}{l}\text { Present in pesticides; can be found as a contaminant in } \\
\text { caustic soda. Mercury compounds may be used in paints }\end{array}$ & $\begin{array}{l}\text { Many parts of the supply chain based on } \\
\text { function }\end{array}$ \\
\hline Nano silver & Antimicrobial fabric treatment & Fabric finishing \\
\hline Organotin compounds & $\begin{array}{l}\text { Plastics/rubbers (polyurethane), inks, glitter, some } \\
\text { adhesives, heat transfer materials }\end{array}$ & $\begin{array}{l}\text { Rubber production, shoe manufacturing, } \\
\text { printing }\end{array}$ \\
\hline \multicolumn{3}{|l|}{ Monomers } \\
\hline Acrylamides & Manufacture of resins, sealants, binders, thickeners, fibres & Various manufacturing processes \\
\hline Acrylonitrile, acrylates and methacrylates & $\begin{array}{l}\text { Production of acrylic yarns ( } 85 \% \text { acrylonitrile, with the } \\
\text { balance often being acrylates.methacrylates) }\end{array}$ & Acrylic yarn manufacturing \\
\hline $\begin{array}{l}\text { Bisphenols including BPA, halogenated bisphenols, epoxy } \\
\text { resins }\end{array}$ & Residual in epoxy resins or polycarbonates & $\begin{array}{l}\text { Shoe manufacturing, outdoor } \\
\text { equipment manufacturing }\end{array}$ \\
\hline Butadiene and styrene & Synthetic rubbers, monomers for $A B S$ & $\begin{array}{l}\text { Shoe manufacturing, outdoor } \\
\text { equipment manufacturing }\end{array}$ \\
\hline $\begin{array}{l}\text { Epoxide and epoxide precursors like ethylene oxide, } \\
\text { propylene oxide, epichlorohydrin }\end{array}$ & Epoxy resins and adhesives & $\begin{array}{l}\text { Shoe manufacturing, outdoor } \\
\text { equipment manufacturing }\end{array}$ \\
\hline Formaldehyde and other short-chain aldehydes & Wrinkle-free coatings & Fabric finishing \\
\hline Isocyanates & $\begin{array}{l}\text { Monomers in polyurethane production and as cross-linkers in } \\
\text { fabric finishing }\end{array}$ & $\begin{array}{l}\text { Polyurethane production, shoe } \\
\text { production, finishing }\end{array}$ \\
\hline Ortho-phthalates & PVC plasticizers for screen printing and coatings & Non-woven manufacturing and printing \\
\hline Vinyl chloride and vinylidene chloride & Waterproof plastic impregnated fabrics, artificial leathers & Non-woven manufacturing and printing \\
\hline
\end{tabular}


Solvents and process aids

Alkyl-phenol Ethoxylates

\section{Aromatic solvents}

Bezene and o-, p- or m-cresol

Carbon disulfide

Chlorinated cleaning solvents

DMF

Glycols

$\mathrm{N}, \mathrm{N}$-dimethylacetamide (DMAC)
Cleaners and detergents

Synthetic leather and manufacturing and can be found in

cleaners and ink solvents

Solvents used in processing and/or adhesives

Rayon and other cellulosic manufacturing

Dry cleaning, spot cleaning, scouring

Swelling/foamimg for polyurethane non-woven

Solvents in finishing, cleaning, printing and adhesive

processes

Solvent for elastane and polyurethane coatings; adhesives
Mills

Leather and dye houses

Shoe manufacturing, outdoor

equipment manufacturing

Rayon fibre production

Garment manufacturing

Materials and chemical suppliers

Fabric finishing, garment manufacture

Material and chemical suppliers 
Wageningen Food Safety Research

P.O. Box 230

6700 AE Wageningen

The Netherlands

T +31 (0)317480256

www.wur.eu/food-safety-research

WFSR report 2019.017
The mission of Wageningen University \& Research is "To explore the potential of nature to improve the quality of life". Under the banner Wageningen University \& Research, Wageningen University and the specialised research institutes of the Wageningen Research Foundation have joined forces in contributing to finding solutions to important questions in the domain of healthy food and living environment. With its roughly 30 branches, 5,000 employees and 12,000 students, Wageningen University \& Research is one of the leading organisations in its domain. The unique Wageningen approach lies in its integrated approach to issues and the collaboration between different disciplines. 



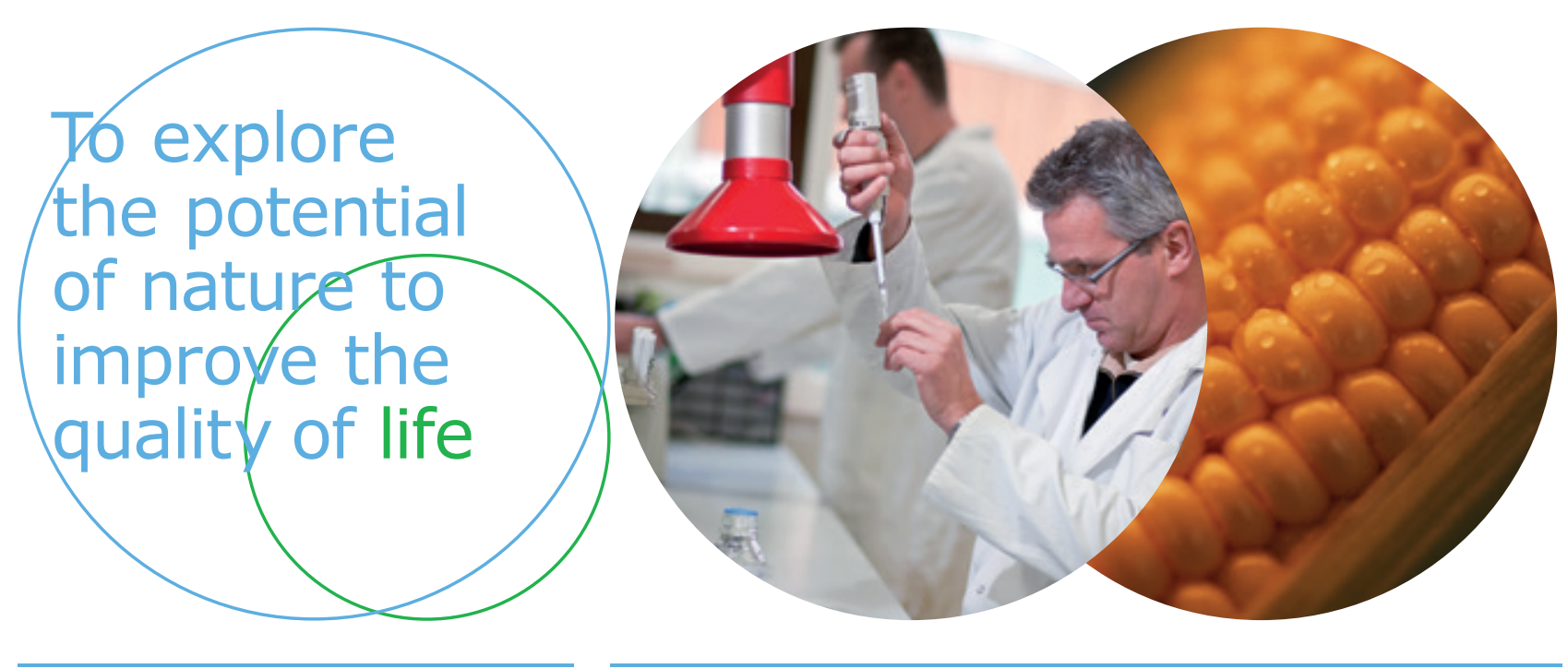

Wageningen Food Safety Research P.O. Box 230

6700 AE Wageningen

The Netherlands

T +31 (0)317480256

www.wur.eu/food-safety-research

WFSR report 2019.017
The mission of Wageningen University \& Research is "To explore the potential of nature to improve the quality of life". Under the banner Wageningen University $\&$ Research, Wageningen University and the specialised research institutes of the Wageningen Research Foundation have joined forces in contributing to inding solutions to important questions in the domain of healthy food and living environment. With its roughly 30 branches, 5,000 employees and 12,000 students, Wageningen University \& Research is one of the leading organisations in its domain. The unique Wageningen approach lies in its integrated approach to issues and the collaboration between different disciplines. 